\title{
Application of 1-aminocyclohexane carboxylic acid to protein nanostructure computer design
}

\author{
Francisco Rodríguez-Ropero ${ }^{1}$, David Zanuy ${ }^{1,}{ }^{*}$, Jordi Casanovas ${ }^{2}$, Ruth Nussinov ${ }^{3,4}$, and \\ Carlos Alemán ${ }^{1}$, \\ ${ }^{1}$ Departament d'Enginyeria Química, E. T. S. d'Enginyeria Industrial de Barcelona, Universitat \\ Politècnica de Catalunya, Diagonal 647, Barcelona E-08028, Spain \\ 2Departament de Química, Escola Politècnica Superior, Universitat de Lleida, c/Jaume II № 69, \\ Lleida E-25001, Spain \\ ${ }^{3}$ Basic Research Program, SAIC-Frederick Inc., Center for Cancer Research, Nanobiology \\ Program, NCl-FCRDC, Frederick, MD 21702 \\ ${ }^{4}$ Sackler Institute of Molecular Medicine, Department of Human Genetics and Molecular Medicine, \\ Sackler School of Medicine, Tel Aviv University, Tel Aviv 69978, Israel
}

\begin{abstract}
Conformationally restricted amino acids are promising candidates to serve as basic pieces in redesigned protein motifs which constitute the basic modules in synthetic nanoconstructs. Here we study the ability of constrained cyclic amino acid 1-aminocyclohexane-1-carboxylic acid $\left(\mathrm{Ac}_{6} \mathrm{c}\right)$ to stabilize highly regular $\beta$-helical motifs excised from naturally occurring proteins. Calculations indicate that the conformational flexibility observed in both the ring and the main chain is significantly higher than that detected for other 1-aminocycloalkane-1-carboxylic acid $\left(\mathrm{Ac}_{\mathrm{n}} \mathrm{c}\right.$, where $n$ refers to the size of the ring) with smaller cycles. Incorporation of $A_{6} c_{6} \mathrm{c}$ into the flexible loops of $\beta$-helical motifs indicates that the stability of such excised building blocks as well as the nanoassemblies derived from them is significantly enhanced. Thus, the intrinsic $\mathrm{Ac}_{6} \mathrm{c}$ tendency to adopt folded conformations combined with the low structural strain of the cyclohexane ring confers the ability to both self-adapt to the $\beta$-helix motif and to stabilize the overall structure by absorbing part of its conformational fluctuations. Comparison with other $\mathrm{Ac}_{\mathrm{n}} \mathrm{c}$ residues indicates that the ability to adapt to the targeted position improves considerably with the ring size, i.e. when the rigidity introduced by the strain of the ring decreases.
\end{abstract}

\section{Introduction}

Synthetic $\alpha$-amino acids 1-aminocycloalkane-1-carboxylic acids $\left(\mathrm{Ac}_{\mathrm{n}} \mathrm{c}\right.$, where $n$ indicates the size of the ring) are the result of $\mathrm{C}^{\alpha} \leftrightarrow \mathrm{C}^{\alpha}$ cyclization whereby dialkylated glycine residues with cyclic side chains are formed. The conformational properties and electronic characteristics of $N$-acetyl- $N$ '-methylamide derivatives of the cyclopropane ${ }^{1}\left(\mathrm{Ac}_{3} \mathrm{c}\right)$, cyclobutane ${ }^{2}\left(\mathrm{Ac}_{4} \mathrm{c}\right)$ and cyclopentane $\mathrm{e}^{3}\left(\mathrm{Ac}_{5} \mathrm{c}\right)$ analogues were fully characterized using ab initio and Density Functional Theory (DFT) quantum chemical calculations. The conformational flexibility of the backbone increases with the size of the ring. In the $\mathrm{Ac}_{5} \mathrm{c}$ dipeptide each accessible backbone conformation is compatible with different arrangements of the cyclopentane ring. ${ }^{3}$ The pseudorotational cyclopentane puckering strongly depends on the peptide backbone structure,

*Correspondence to: david.zanuy@upc.edu and carlos.aleman@upc.edu . 
that is, the arrangement of the cycle is determined by interactions between the side chain and the backbone.

When re-engineering protein modules via targeted replacements with synthetic amino acids, 4 the stability of self-assembled $\beta$-helical-based constructs, which should be considered as nanotubes or nanofibers, increases when the mobility of the loop regions is reduced by incorporating conformationally restricted amino acids. ${ }^{5,6}$ Previously we examined the stability of $\beta$-helical nanoconstructs following introduction of $\mathrm{Ac}_{3} \mathrm{c}$ and 1-amino-2,2-diphenylcyclopropanecarboxylic acid ( $\mathrm{c}_{3} \mathrm{Dip}$ ), an $\mathrm{Ac}_{3} \mathrm{c}$ analogue bearing two phenyl rings at geminal positions, into flexible regions of the $\beta$-helical building blocks. Position-specific mutations indicated that when $\mathrm{Ac}_{3} \mathrm{c}$ is introduced in loop regions it is able to enhance the stability of the nanoconstucts due to its strong tendency to adopt a turn structure, while $c_{3}$ Dip is unsuccessful due to the steric effects induced by the bulky side chain. .56

Here we report a complete study about the stability of $\beta$-helical-based nanostructures when 1aminocyclohexane-1-carboxylic acid $\left(\mathrm{Ac}_{6} \mathrm{c}\right)$ is introduced in the loop region proteins. Early studies on small linear $\mathrm{Ac}_{6} \mathrm{c}$-containing peptides indicated that this amino acid tends to be involved in $\beta$-turns suggesting that this synthetic amino acid is a potential candidate to increase the stability of nanoconstructs. Crystal state structural analyses indicated that this residue can occupy either the corner position $(i+1, i+2)$ of type I $\beta$-bend or the $i+2$ position of type II $\beta$ bends, ${ }^{7-10}$ that is, the backbone conformation adopted by the $\mathrm{Ac}_{6} \mathrm{c}$ is located in the helical region $\left(\varphi, \psi \approx \pm 55^{\circ}, \pm 30^{\circ}\right)$. Similarly, ${ }^{1} \mathrm{H}-\mathrm{NMR}$ and FTIR studies in solution indicated that small oligomers of $\mathrm{Ac}_{6} \mathrm{c}$ tend to form (incipient) helical secondary structures. ${ }^{11}$ In cyclic peptides the $\mathrm{Ac}_{6} \mathrm{c}$ residue adopts conformations in the helical region leading to $\beta$-bends. ${ }^{12}$ On the other hand, $\mathrm{Ac}_{6} \mathrm{c}$ was recently introduced in position 8 of bradykinin and positions 6,7 and 8 of its $\mathrm{B}_{2}$ receptor antagonist to reduce the flexibility of the peptides, thus forcing the peptide backbone and side chains to adopt specific orientations. ${ }^{13}$ Interestingly, the $\mathrm{Ac}_{6} \mathrm{c}$ substitution resulted in an increase in $B_{2}$ antagonistic activity, which offered new possibilities for designing new potent and selective $\mathrm{B}_{2}$ blockers. Biological and pharmaceutical properties of several $\mathrm{Ac}_{6} \mathrm{c}$-containing peptides have been evaluated, some showing highly potent antidiuretic activity. ${ }^{14}$ However, in spite of all these studies, no accurate description about the intrinsic conformational preferences of $\mathrm{Ac}_{6} \mathrm{c}$ has been previously reported.

The aim of this work is to report the overall of the results of a four-steps project that involve: (i) the characterization of the conformational properties of $\mathrm{Ac}_{6} \mathrm{c}$; (ii) the influence of the environment in such properties; (iii) the development of force-field parameters for this synthetic amino acid; and finally (iv) a complete study about how the incorporation of $A_{6} \mathrm{c}$ within the more flexible regions of the $\beta$-helical building blocks affects to the stability of selfassembled nanoconstructs. The paper has been organized as follows. First, we present the computational procedures used to examine the intrinsic conformational properties of $\mathrm{Ac}_{6} \mathrm{c}$ and the stability of protein nanostructures that incorporate this constrained amino acid at the more flexible regions of the protein building blocks. The minimum energy conformations and the Ramachandran maps of the $N$-acetyl- $N$ '-methylamide derivative of $\mathrm{Ac}_{6} \mathrm{c}$ (Scheme 1), hereafter denoted $\mathrm{Ac}_{-} \mathrm{Ac}_{6} \mathrm{c}-\mathrm{NHMe}$, calculated in the gas-phase and solution (chloroform, methanol and water solvents) are compared and discussed. After this, a set of force-field parameters has been developed for $\mathrm{Ac}_{6} \mathrm{c}$ to allow molecular dynamics simulations (MD). The suitability of such parameters has been checked by comparing the conformational preferences predicted for Ac$\mathrm{Ac}_{6} \mathrm{c}-\mathrm{NHMe}$ by DFT calculations and MD simulations. Next, we examine if $\mathrm{Ac}_{6} \mathrm{c}$ is a good candidate to increase the stability of both the $\beta$-helical protein building blocks and the nanoconstructs formed by self-assembling of such repeats. For this purpose we considered as building blocks the left-handed $\beta$-helices formed by residues 131-165 of E. coli galactoside acetyltransferase (PDB code 1 krr, chain A) and by residues 296-329 of N-acetylglucosamine 1-phosphate uridyltransferase GlmU, C-terminal domain from E. coli (PDB code 1hv9) that, 
in our earlier study, were found to form the most and least stable protein nanotubes, respectively. ${ }^{15}$ Finally, to further address the potential use of conformationally restricted amino acids to stabilize natural building block foldamers, the stabilizing effect produced by $\mathrm{Ac}_{3} \mathrm{c}$ and $\mathrm{Ac}_{6} \mathrm{c}$ substitutions are compared.

\section{Methods}

Quantum chemical calculations were carried out using the Gaussian 03 program. ${ }^{16}$ All the

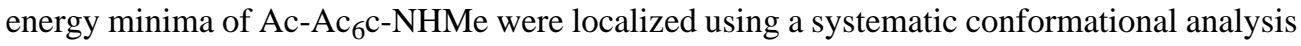
strategy. Specifically, because each flexible backbone dihedral angle is expected to have three minima, i.e. gauche $e^{+}\left(60^{\circ}\right)$, trans $\left(180^{\circ}\right)$ and gauche ${ }^{-}\left(-60^{\circ}\right)$, the number of minima that may be anticipated for the potential energy hypersurface $\mathrm{E}=\mathrm{E}(\varphi, \psi)$ of $\mathrm{Ac}_{\mathrm{c}} \mathrm{Ac}_{6} \mathrm{c}-\mathrm{NHMe}$ is $3^{2}=9$. Furthermore, due to the cyclic nature of the side chain, two chair and one boat (labeled as $\mathrm{S}_{1}$, $\mathrm{S}_{2}$ and B, respectively, in Scheme 2) arrangements of the cyclohexane side chain have been considered for each backbone minimum energy conformation. We are aware that another boat conformation can be obtained by exchanging the positions of the NHAc and CONHMe moieties. However, this alternative boat arrangement is expected to be of the highest energy and, therefore, it has not been included in the conformational analysis. Accordingly, such $9 \times 3=$ 27 structures were considered as starting points for complete geometry optimization.

This systematic strategy permitted satisfactory exploration of the potential energy hypersurfaces not only of small dipeptides ${ }^{1-3}$ but also of flexible organic molecules. ${ }^{17}$ Frequency analyses were carried out to verify the nature of the minimum state of all the stationary points obtained and to calculate the zero-point vibrational energies (ZPVE) and both thermal and entropic corrections. These statistical terms were used to compute the conformational Gibbs free energies in the gas-phase at $298 \mathrm{~K}\left(\Delta \mathrm{G}^{\mathrm{gp}}\right)$. All the calculations were carried out using the B3LYP ${ }^{18,19}$ functional and the $6-31+\mathrm{G}(\mathrm{d}, \mathrm{p})$ basis set. ${ }^{20}$

A complete exploration of the potential energy surface $\mathrm{E}(\varphi, \psi)$ was performed by mapping the Ramachandran plot of Ac- $\mathrm{Ac}_{6} \mathrm{c}-\mathrm{NHMe}$. Calculations were performed on a grid of points on the $(\varphi, \psi)$ space at $30^{\circ}$ intervals, $\omega_{1}$ and $\omega_{2}$ being initially positioned at $180^{\circ}$ in all cases. Due to the achiral nature of the molecule, only half of the map was computed since $\mathrm{E}(\varphi, \psi)=\mathrm{E}(-\varphi$, $-\psi)$. At each point of the grid the geometry was optimized in the gas-phase by keeping the dihedral angles $\varphi$ and $\psi$ constrained during the minimization process.

To calculate the Ramachandran map of $\mathrm{Ac}_{-} \mathrm{Ac}_{6} \mathrm{c}-\mathrm{NHMe}$ in solution and to obtain estimation of the solvation effects on the relative stability of the different minima, single point calculations were also conducted on the B3LYP/6-31+G(d,p) optimized structures using a Self-Consistent Reaction Field (SCRF) model. SCRF methods treat the solute at the quantum mechanical level, while the solvent is represented as a dielectric continuum. Specifically, we chose the Polarizable Continuum Model (PCM) developed by Tomasi and co-workers to describe the bulk solvent. ${ }^{21,22}$ The PCM method involves the generation of a solvent cavity from spheres centered at each atom in the molecule and the calculation of virtual point charges on the cavity surface representing the polarization of the solvent. The magnitude of these charges is proportional to the derivative of the solute electrostatic potential at each point calculated from the molecular wavefunction. The point charges may, then, be included in the one-electron Hamiltonian, thus inducing polarization of the solute. An iterative calculation is carried out until the wavefunction and the surface charges are self-consistent. PCM calculations were also performed in the framework of the DFT B3LYP/6-31+G(d,p) level using the standard protocol and considering the dielectric constants of chloroform $(\varepsilon=4.9)$, methanol $(\varepsilon=32.63)$ and water $(\varepsilon=78.4)$. The conformational free energies in solutions $\left(\Delta G^{\# s o l \#}\right.$, where \#sol\# refer to the solvent) were computed using the classical thermodynamics scheme: the free energies of solvation provided by the PCM model were added to the $\Delta \mathrm{G}^{\mathrm{gp}}$. 
Molecular Dynamics (MD) simulations were performed using the NAMD program. ${ }^{23}$ Each simulated system was placed in the center of a simulation box filled with explicit water molecules, which were represented using the TIP3P model. ${ }^{24}$ Positively charged sodium atoms were added to the simulation box in the required amount to reach electric neutrality (all considered building blocks had negative net charge at neutral $\mathrm{pH}$ ). All atoms of both building blocks and nanotubes were considered explicitly.

The energy was calculated using the AMBER force-field, ${ }^{25,26}$ with the required parameters taken from the AMBER libraries for all the residues with the exception of $A_{6} c_{6}$. Force-field parameters for $\mathrm{Ac}_{6} \mathrm{C}$ were developed using the same strategy that we previously employed for $\mathrm{Ac}_{5} \mathrm{c}{ }^{3}$ As was be demonstrated, the parameters provided by such strategy are fully consistent with AMBER ones. Atom pair distance cutoffs were applied at $14.0 \AA$ to compute the van der Waals interactions. The electrostatic interactions were computed using the non-truncated electrostatic potential with Ewald Summations. ${ }^{27}$ The real space term was determined by the van der Waals cut off $(14.0 \AA)$, while the reciprocal term was estimated by interpolation of the effective charge into a charges mesh with a grid thickness 5 points per volume unit, i.e. particlemesh Ewald (PME) method. ${ }^{27}$ Bond lengths involving hydrogen atoms were constrained using the $S H A K E$ algorithm, ${ }^{28}$ with a numerical integration step of $2 \mathrm{fs}$. The initial edge of the cubic box for simulations of wild type and mutated building blocks was $56.6 \AA$, the total number of particles considered explicitly ranging from 17465 to 17487 . For simulations of the selfassembled nanotube, the initial dimensions of the tetragonal box were $(72.0 \times 72.0 \times 112.0)$ $\AA^{3}$ and the number of explicit particles ranged from 56084 to 56196 .

Before the production series, the thermodynamic variables of the system were equilibrated. The energy of each system was initially minimized to relax conformational and structural tensions using the conjugate gradient method for $5 \cdot 10^{3}$ steps. Next, different consecutive rounds of short MD runs were performed in order to equilibrate the density, temperature and pressure. First, solvent and charged sodium atoms were thermally relaxed by three consecutives runs, while the protein parts were kept frozen: $0.5 \mathrm{~ns}$ of NVT-MD at $500 \mathrm{~K}$ were used to homogeneously distribute the solvent and ions in the box. Second, $0.5 \mathrm{~ns}$ of isothermal and 0.5 $\mathrm{ns}$ isobaric relaxation were run. Finally, all the atoms of the system were submitted to $0.15 \mathrm{~ns}$ of steady heating until the target temperature was reached ( $298 \mathrm{~K}$ ), $0.25 \mathrm{~ns}$ of $N V T$-MD at 298 $\mathrm{K}$ (thermal equilibration) followed by $0.5 \mathrm{~ns}$ of density relaxation (NPT-MD). Both temperature and pressure were controlled by the weak coupling method, the Berendsen thermo-barostat,

${ }^{29}$ using a time constant for heat bath coupling and a pressure relaxation time of $1 \mathrm{ps}$. The end of the density relaxation simulation was the starting point of the molecular simulations presented in this work. All the simulations were performed at $298 \mathrm{~K}$ and constant pressure of $1 \mathrm{~atm}$. The coordinates of all the production runs, which were $10 \mathrm{~ns}$ long, were saved every 500 steps ( 1 ps intervals) for subsequent analysis.

\section{Results and Discussion}

\section{Intrinsic Conformational Properties of $\mathrm{Ac}_{6} \mathrm{C}$}

Geometry optimizations in the gas-phase at the B3LYP/6-31+G(d,p) level of the 27 structures considered as starting geometries (see Methods), led to 11 different minimum energy structures

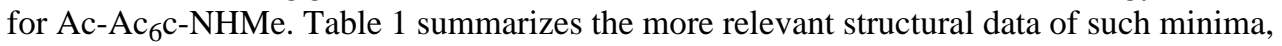
which are depicted in Figure 1. Within this context, it should be mentioned that the criterion used to accept the formation of an intramolecular hydrogen bond was: $d(\mathrm{H} \cdots \mathrm{O})<2.5 \AA$.

The two minima more stable in the gas-phase, I and II, correspond to a $C_{7}$ ( $\gamma$-turn), in which the backbone dihedral angles $\varphi, \psi$ define a seven-membered intramolecular hydrogen bonded ring with parameters $d(\mathrm{H} \cdots \mathrm{O})=1.907$ (I) $/ 1.938$ (II) $\AA$ and $\angle \mathrm{N}-\mathrm{H} \cdots \mathrm{O}=151.7^{\circ}$ (I) $/ 147.9^{\circ}$ (II). In these minima, which differ in $0.2 \mathrm{kcal} / \mathrm{mol}$, the cyclohexane ring adopts a $S_{1}$ and $S_{2}$ 
conformation, respectively. Thus, in this case the two chair arrangements show similar stabilities. However, minimum VIII, in which the $\mathrm{C}_{7}$ backbone conformation and the $\mathrm{B}$ arrangement for the cyclohexane ring are combined, is disfavored by $6.0 \mathrm{kcal} / \mathrm{mol}$ with respect to I.

Minimum III corresponds to an $\alpha$-helical conformation with the cyclohexane arranged in $\mathrm{S}_{1}$. No intramolecular hydrogen bonding interaction is present in this structure, which is $2.5 \mathrm{kcal} /$ mol less stable than the global minimum I. The analogous $\alpha$-helical minimum but with the cyclohexane arranged in $\mathrm{S}_{2}$, VI, is destabilized by $1.3 \mathrm{kcal} / \mathrm{mol}$ with respect to III. In this case, no B arrangement was compatible with the $\alpha$-helical backbone conformation. Comparison of these results with those obtained for I and II indicates that the $S_{1} \leftrightarrow S_{2}$ equilibrium is significantly influenced by the backbone conformation. This influence becomes more apparent in minima IV, VII and XI, in which the $\mathrm{P}_{\mathrm{II}}$ backbone arrangement is compatible with the $\mathrm{S}_{1}$, $\mathrm{S}_{2}$ and B conformations, respectively. The chair conformation with the CONHMe moiety in an equatorial position $\left(S_{1}\right)$ is more stable than the structure that adopts a $S_{2}$ conformation by $3.0 \mathrm{kcal} / \mathrm{mol}$, the B arrangement being destabilized by $6.4 \mathrm{kcal} / \mathrm{mol}$.

Finally, the least favored backbone conformation corresponds to the $\mathrm{C}_{5}$, which is displayed by minima V, IX and X. In these structures the backbone dihedral angles $\varphi, \psi$ are arranged in trans, defining a five-membered intramolecular hydrogen bonded ring with parameters $d(\mathrm{H} \cdots \mathrm{O})=$ 1.974 (V) / 1.922 (IX) / 2.021 (X) $\AA$ and $\angle \mathrm{N}-\mathrm{H} \cdots \mathrm{O}=114.2^{\circ}$ (V) / $117.9^{\circ}$ (IX) / 112.5 $5^{\circ}$ (X). The V, IX and X minima, which show steric repulsions between the amide groups and the $\beta$ methylene hydrogen atoms, are destabilized by $3.4,6.2$ and $7.5 \mathrm{kcal} / \mathrm{mol}$, respectively, with respect to the global minimum I. For the $\mathrm{C}_{5}$ the $\mathrm{S}_{2}$ chair conformation is the most stable arrangement of the cyclohexane ring. Table 2 lists the values of $\Delta \mathrm{G}^{\mathrm{gp}}$ for the 11 minima. As can be seen, the influence of the ZPVE, thermal and entropic corrections do not introduce significant changes in the stability of these structures, the maximum difference between $\Delta \mathrm{E}$ and $\Delta \mathrm{G}^{\mathrm{gp}}$ being $1.3 \mathrm{kcal} / \mathrm{mol}$ (minimum $\mathrm{V}$ ).

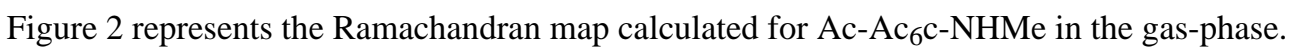
The map was obtained by considering the $S_{1}$ as the starting conformation for the cyclohexane ring of all the calculated structures on the $(\varphi, \psi)$ space. Although this chair conformation was frequently retained after geometry optimization, in some cases the $S_{1}$ transform into the $S_{2}$ or, even, the boat arrangements. As expected, the four backbone conformations listed in Table 1 correspond to low energy regions in the map. Comparison of the map calculated for $\mathrm{Ac}_{\mathrm{c}} \mathrm{Ac}_{6} \mathrm{c}-$ $\mathrm{NHMe}$ with those previously reported for $\mathrm{Ac}-\mathrm{Ac}_{4} \mathrm{c}-\mathrm{NHMe}^{2}$ and $\mathrm{Ac}-\mathrm{Ac}_{3} \mathrm{c}-\mathrm{NHMe}^{1}$ evidence that the conformational flexibility of $\mathrm{Ac}_{\mathrm{n}} \mathrm{c}$-containing dipeptides increases with the size of the ring. Thus, although $A_{6} \mathrm{c}$ is a constrained amino acid, the number of low energy regions is significantly smaller for $\mathrm{Ac}_{4} \mathrm{c}$ and $\mathrm{Ac}_{3} \mathrm{c}$.

The Ramachandran maps calculated in chloroform, methanol and water solutions are displayed in Figure 3. The topology of these maps is different from that obtained in the gas-phase indicating that the solvent plays a crucial role in the conformational preferences of $\mathrm{Ac}_{6} \mathrm{c}$. Specifically, Figure 3 reveals that the relative energy range that separates the most and least favored conformations is drastically reduced by the solvent. This is also indicated in Table 2, which compares the conformational free energies in solutions for the 11 minimum energy structures for $\mathrm{Ac}_{-} \mathrm{Ac}_{6} \mathrm{c}-\mathrm{NHMe}$. Interestingly, although the relative free energy order of these structures is very similar in the gas-phase and in a chloroform solution, the free energy range for the first 6 minima is significantly narrower in the latter organic solvent, i.e. they are separated by 3.5 and $1.8 \mathrm{kcal} / \mathrm{mol}$ in the gas-phase and chloroform solution, respectively. The effect of the solvent is even more pronounced in methanol and water, in which a substantial change in the relative conformational free energy order is detected. Thus, minimum VI is the most favored in these polar environments. Overall, these results indicate that the 
conformational restrictions imposed by the cyclohexane ring are less severe in solution than in the gas-phase, the role of the solute-solvent interactions being crucial for the conformational preferences of $\mathrm{Ac}_{6} \mathrm{c}$ in the former environment.

\section{Force-Field Parametrization}

Electrostatic charges have been the only force-field parameters specifically developed for $\mathrm{Ac}_{6} \mathrm{c}$, the stretching, bending, torsional and van der Waals parameters being directly transferred from the Amber force-field. ${ }^{25,26}$

Atomic charges for all eleven minimum energy conformations listed in Table 1 were calculated by fitting the HF/6-31G(d) quantum mechanical and the Coulombic molecular electrostatic potentials (MEPs) to a large set of points placed outside the nuclear region. It should be noted that the electrostatic parameters derived at this level of theory are fully compatible with the current Amber force-field. ${ }^{25,26}$ Electrostatic potential (ESP) fitting atomic centered charges for the $\mathrm{Ac}_{6} \mathrm{c}$ residue were derived by weighting the charges calculated for the eleven minimum energy conformations according to the Boltzmann populations. The weights were given by the standard Boltzmann formula using the $\Delta \mathrm{G}^{\mathrm{gp}}$ values listed in Table 2, i.e. in practice only minima I and II contributed significantly. The resulting electrostatic parameters are displayed in Figure 4.

An important test to check the reliability of force-field parameters developed for amino acids is the attempt to reproduce both the energetically accessible conformations of dipeptides and their flexibility. ${ }^{3,25,26}$ In order to ascertain how the force-field parameters describe these properties $\mathrm{Ac}_{-} \mathrm{Ac}_{6} \mathrm{c}-\mathrm{NHMe}$, MD simulations were performed at $298 \mathrm{~K}$ in the gas-phase. The three conformations of lower energy were used as starting point, each trajectory being $8 \mathrm{~ns}$ long. Figure 5 represents the accumulated Ramachandran plot of the three trajectories for the $\mathrm{Ac}_{6} \mathrm{c}$ dipeptide. It is worth noting the $\mathrm{C}_{7}$ and $\alpha$ are the populated regions, in excellent agreement with the $\Delta \mathrm{G}^{\mathrm{gp}}$ values derived from DFT calculations (Table 2). On the other hand, as expected a chair conformation was systematically detected for the cyclohexane ring.

\section{Building Block Mutants of $1 \mathrm{krr}$ and $1 \mathrm{hv9}$}

DFT calculations on $A c-\mathrm{Ac}_{6} \mathrm{c}-\mathrm{NHMe}$ indicated that $\mathrm{Ac}_{6} \mathrm{c}$ presents a high propensity to adopt folded conformations. This conformational characteristic makes this synthetic amino acid a potential candidate to reduce the conformational freedom of the $\beta$-helix building blocks if it is introduced in the most mobile regions, i.e. the folded loops, replacing natural amino acids. The strain energy associated with the cyclohexane ring in $\mathrm{Ac}_{6} \mathrm{c}$ is significantly lower than that of other recently investigated constrained amino acids with cyclic side chains, $A_{3} c$ and $c_{3}$ Dip.

5,6 Accordingly, $\mathrm{Ac}_{6} \mathrm{c}$ is expected to adapt its folded conformation within the targeted position more easily than the corresponding analogue with a cyclopropane ring. Two $\mathrm{Ac}_{6} \mathrm{c}$-single mutations were considered for the $1 \mathrm{krr}$ and $1 \mathrm{hv} 9 \beta$-helix building blocks. ${ }^{15} \mathrm{We}$ found that a nanostructure constructed by four stacked replicas of the left-handed $\beta$-helix formed by residues $131-165$ of $1 \mathrm{krr}$ exhibited remarkable stability under different simulated conditions, including temperature increase and addition of ions. ${ }^{15}$ On the other hand, the less stable model was obtained from four self-assembled copies of the $\beta$-helix formed by residues 296-329 of $1 \mathrm{hv} 9$. Thus, nanoconstructs formed by the latter repeat are good systems to test stabilization strategies. A description of the sequences of $1 \mathrm{krr}$ and $1 \mathrm{hv} 9$ building blocks is provided in Table 3.

Two positions of $1 \mathrm{krr}$ and $1 \mathrm{hv} 9$ building blocks were selected as suitable candidates for substitution by $\mathrm{Ac}_{6} \mathrm{c}$ according to the following criteria (Figure 6): i) the residues are located in the loop regions of the $\beta$-helix, which display higher mobility than the $\beta$ sheets and present a folded conformation similar to that preferred by $A_{6} c$; ii) the side chain of the residues is 
outward-pointing avoiding unfavorable steric interactions between the cyclohexane group of the $\mathrm{Ac}_{6} \mathrm{c}$ substitution and the side chains of the inward-pointing residues. Targeting flexible disfavored loop regions should have direct impact on the structural stability of the nanotubes. For the $1 \mathrm{krr}$ building block the Gly-149 and Ala-160 residues were substituted by the $\mathrm{Ac}_{6} \mathrm{c}$ one at a time (Table 3), the two corresponding mutants being denoted $\mathrm{G} 149 \mathrm{Ac}_{6} \mathrm{c}$ and $\mathrm{A} 160 \mathrm{Ac}_{6} \mathrm{c}$, respectively. The single mutations performed on the $1 \mathrm{hv} 9$ building block at Asp-306 and Ala-322 were denoted D306Ac ${ }_{6} \mathrm{c}$ and A322Ac 6 c, respectively. The charged side chain of Asp-306 produces electrostatic repulsions with Asp-305 in the loop region of 1hv9. ${ }^{15}$

Figure 7 compares the root mean square deviation (RMSD) of the wild type with the corresponding mutants, while Figure 8 displays for each case the initial structure with that obtained after $10 \mathrm{~ns}$ of MD simulation. As can be seen, replacement of Gly-149 by $\mathrm{Ac}_{6} \mathrm{c}$ produced an improvement in the RMSD of the $1 \mathrm{krr}$ building block. Such improvement is clearly observed in Figure 9, which shows the root mean square fluctuation (RMSF) of individual residues averaged over the whole simulation. Analysis of the RMSF reveals a considerable local improvement, the averaged RMSD of residue 149 decreasing by about $1.5 \AA$.

Accordingly, substitution of a flexible Gly residue by an $\mathrm{Ac}_{6} \mathrm{c}$, which is constrained to adopt turn conformations, stabilizes the bend architecture of the loop by reducing its mobility. In contrast, neither local nor global improvement was observed for the $\mathrm{A} 160 \mathrm{Ac}_{6} \mathrm{c}$ mutant. The RMSD of residue 160 increased by $1.17 \AA$ after mutation (Figure 9). A detailed examination of the snapshot recorded for this mutant at the end of the simulation (Figure 8) reveals a significant distortion in the turn at positions $159-161$, indicating that the rigidity introduced by the synthetic residue in the loop causes the disruption of the $\beta$-helix motif (see Ramachandran plots in the Supporting Information). This feature suggests that in order to retain the global organization of the building block it is important to preserve some flexibility in this loop.

For the wild type building block of $1 \mathrm{hv} 9$ and its mutants, results indicate that the $\mathrm{D} 306 \mathrm{Ac}_{6} \mathrm{c}$ mutant shows a notable structural stability. In this case, the RMSF is considerably smaller at many positions along the chain. The initial $\beta$-helix conformation is retained without apparent distortions after $10 \mathrm{~ns}$ of MD simulation. Inspection of the Ramachandran plots of the substituted position and the adjacent residues (Supporting Information) reveals a significant resemblance between the wild type and the $\mathrm{D}^{2} 06 \mathrm{Ac}_{6} \mathrm{C}$ mutant. Analysis of the RMSF indicates that even though the substitution at position Asp-306 by $\mathrm{Ac}_{6} \mathrm{c}$ eliminates the electrostatic repulsion with Asp-305, the backbone constraints associated with the $\mathrm{Ac}_{6} \mathrm{c}$ residue have a significantly smaller effect in the fluctuations at the loop than at the other positions along the chain. As a consequence, a substantial global stabilization of the building block is obtained. By contrast, substitution at Ala-322 does not provide neither local nor global improvement. The structural distortion is significant for both the wild type and the $\mathrm{A} 322 \mathrm{Ac}_{6} \mathrm{c}$ mutant, with the $\beta$-helix disrupted in both cases.

Analysis of the conformation adopted by the cyclic side chain of $\mathrm{Ac}_{6} \mathrm{c}$ through the MD simulations of $1 \mathrm{krr}$ and $1 \mathrm{hv} 9$ mutants reveals a certain degree of mobility. Although the $\mathrm{S}_{1}$ is clearly the predominant conformation in all cases (population of 67\%), relatively high populations of both $\mathrm{S}_{2}$ and B arrangements are detected (21\% and $12 \%$, respectively). However, the apparition of the latter arrangements should be attributed to relaxation effects associated to the dynamics of the building block, rather than to a thermodynamic equilibrium. This feature indicates that the flexibility of the cyclohexane ring plays a crucial role in the adaptation of the $\mathrm{Ac}_{6} \mathrm{c}$ residue to the bend organization of the loop. Thus, although the intrinsic stability of wild type building blocks increases by restricting the conformational freedom at a specific position within the most mobile loop, the synthetic residue introduced for this purpose 
should retain some flexibility (for example in the side chain, as $\mathrm{Ac}_{6} \mathrm{c}$ ) to avoid unfavorable strain effects that disturb this architecture.

\section{Assembled Mutants of $1 \mathrm{krr}$ and $\mathbf{1 h v 9}$}

G149Ac $6 \mathrm{c}_{6} \mathrm{c}, \mathrm{A} 160 \mathrm{Ac}_{6} \mathrm{c}, \mathrm{D} 306 \mathrm{Ac}_{6} \mathrm{c}$ and $\mathrm{A} 322 \mathrm{Ac}_{6} \mathrm{c}$ were used as building blocks for nanoassemblies, which were constructed by stacking four copies of each repeat one atop the other, with no covalent linkage between them. Figure 10 compares the evolution of the RMSD calculated for nanotubes of the mutated building blocks with those obtained using wild-type repeats, while Figure 11 depicts the structure of the nanoconstructs after $10 \mathrm{~ns}$ of MD. Finally, Figure 12 shows the RMSF of all the investigated systems.

As expected from the results of the single building block, the RMSD of the G149Ac 6 c selfassembled system is significantly smaller than that derived from $1 \mathrm{krr}$ wild type repeat. At 298 $\mathrm{K}$, the backbone RMSD of the self-assembled G149Ac 6 c remains below $1 \AA$ for the entire simulation indicating the stability of this organization is remarkably high. This behavior demonstrates that the substitution of Gly-149 by $\mathrm{Ac}_{6} \mathrm{c}$ not only reduces the flexibility of the building block but also enhances its ability to retain the assembled nanostructure constructed using the mutated subunits. This feature is clearly indicated by the Ramachandran plots provided in the Supporting Information, which reflect not only the low mobility of the whole mutated loops but also the remarkable conformational similarity among the four $\mathrm{Ac}_{6} \mathrm{c}$ residues contained in the different subunits of the self-assembled G149Ac ${ }_{6} \mathrm{c}$. On the other hand, inspection to the RMSD and RMSF of the $\mathrm{A} 160 \mathrm{Ac}_{6} \mathrm{c}$ mutant indicates that self-assembling does not provide any improvement of the local organization with respect to that observed for the building block. Indeed, Figure 11 shows that the fourth building block is completely unfolded after $10 \mathrm{~ns}$ of MD simulation. To conclude, restricting the conformational freedom at a specific position within the most mobile loop significantly enhances the intrinsic stability of $1 \mathrm{krr}$ self-assembled nanotubes.

Comparison of the self-assembled nanostructure derived from $\mathrm{D} 306 \mathrm{Ac}_{6} \mathrm{c}$ with that constructed using the $1 \mathrm{hv} 9$ wild type building block is provided in Figure 10b. As can be seen, substitution in the self-assembled tube produces a slight improvement. After $10 \mathrm{~ns}$ of MD simulation the RMSD of the D306 $\mathrm{Ac}_{6} \mathrm{c}$ self-assembled tubes is about $1 \AA$ smaller than that of the $1 \mathrm{hv} 9$ nanoconstruct. However, inspection of the RMSF values reveals that the mutation at the Asp-306 produces a partial fraying at the C-terminal region of all the interacting subunits, even though a slight improvement is observed at some residues located at the $\mathrm{N}$-terminal and central regions. These results indicate that although electrostatic repulsions were removed in the mutated building block, they partly reappear when the Asp-305 residues of the stacked D306 $\mathrm{Ac}_{6} \mathrm{c}$ units interact. Finally, the results obtained for the $\mathrm{A} 322 \mathrm{Ac}_{6} \mathrm{c}$ self-assembled nanotube clearly indicate that mutation at the Ala-322 position destabilize not only the building block but also the nanoconstruct. This is probably consequence of the steric interactions produced by the cyclohexane side chain. Figure 11 reveals that the self-assembled organization is completely lost after $10 \mathrm{~ns}$ of MD simulation.

\section{Comparison of the Stabilizing Effect Produced by $\mathrm{Ac}_{3} \mathrm{C}$ and $\mathrm{Ac}_{6} \mathrm{C}$ Substitutions}

In our recent study, ${ }^{5} \mathrm{MD}$ simulations showed that when $\mathrm{Ac}_{3} \mathrm{C}$ is introduced in the loop regions of $1 \mathrm{krr}$ and $1 \mathrm{hv} 9$, it is able to enhance the stability of the nanostructures due to its highly strained backbone and strong tendency to adopt turn conformations. We found that substitutions of the middle Ala by $\mathrm{Ac}_{3} \mathrm{c}$ in different Gly-Ala-Gly and Ala-Ala-Ala motifs lead to remarkable stability, which implies that these motifs are potential targets for $\mathrm{Ac}_{3} \mathrm{c}-$-mutations. Although the conformational preferences of $\mathrm{Ac}_{3} \mathrm{C}$ are severely restrained by the strain of the cyclopropane ring, ${ }^{1}$ the whole mutated motif self-adapts to the regular $\beta$-helical organization by altering the backbone dihedral angles of the neighboring Gly and Ala residues. The latter residues act as a 
flexible hinge to absorb the tension induced by the cyclopropane ring in the loop, i.e. their flexible backbone allows a conformational adjustment.

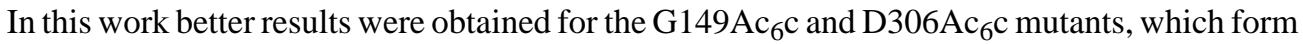
self-assembled nanotubes with higher stability than those derived from $1 \mathrm{krr}$ and $1 \mathrm{hv} 9$ wild type, respectively. In these mutants the middle position of Pro-Gly-Val and Asp-Asp-Cys motifs is substituted by $A_{6} \mathrm{c}$. The introduction of $\mathrm{Ac}_{6} \mathrm{c}$ overcomes the limitations detected in $\mathrm{Ac}_{3} \mathrm{c}$-mutants. This should be attributed to the enhancement of conformational freedom provided by the cyclohexane ring with respect to the cyclopropane. The backbone of $\mathrm{Ac}_{6} \mathrm{C}$ is more flexible than that of $\mathrm{Ac}_{3} \mathrm{c}$ and different arrangements of the cyclohexane ring are compatible with each backbone conformation.

\section{Conclusions}

The intrinsic conformational preferences of $\mathrm{Ac}_{6} \mathrm{c}$ have been examined using DFT calculations in the gas-phase at the B3LYP/6-31+G(d,p) level. Results indicated that $\mathrm{Ac}-\mathrm{Ac}_{6} \mathrm{c}-\mathrm{NHMe}$ tends to adopt folded conformations, as is usual in $\mathrm{Ac}_{\mathrm{n}} \mathrm{c}$ dipeptides, even though its conformational freedom is higher than that of the corresponding $\mathrm{Ac}_{3} \mathrm{c}, \mathrm{Ac}_{4} \mathrm{c}$ and $\mathrm{Ac}_{5} \mathrm{c}$ analogues. This partial flexibility is mainly the consequence of the lack of strain in the cyclohexane ring. The influence of the environment on these conformational preferences has been examined using the PCM model to represent chloroform, methanol and aqueous solutions. Results indicated that the conformational freedom increases with the polarity of the solvent. Our calculations lead us to conclude that even though $\mathrm{Ac}_{6} \mathrm{c}$ is a conformationally constrained amino acid its rigidity is significantly lower than that of other related compounds, i.e. $\mathrm{Ac}_{\mathrm{n}} \mathrm{c}$ with $n<6$, making it a potential candidate to stabilize nanoconstructs.

Here, we introduced $\mathrm{Ac}_{6} \mathrm{c}$ in loop regions of $1 \mathrm{krr}$ and $1 \mathrm{hv} 9$ building blocks to examine the effect of a conformational confinement on the stability of protein nanostructures. We observed that (i) for the more stable $1 \mathrm{krr}$ the substitution of Gly-149 by $\mathrm{Ac}_{6} \mathrm{c}$ has further reduced significantly the conformational mobility not only at the mutated position but also of adjacent

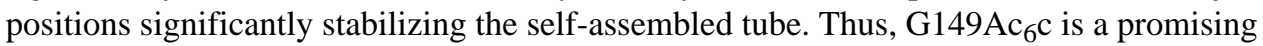
mutant of $1 \mathrm{krr}$; (ii) substitution of Asp-306 by $\mathrm{Ac}_{6} \mathrm{c}$ in the wild type unstable $1 \mathrm{hv} 9$ induces a remarkable structural stability especially in the building block, which we attribute to the partial elimination of unfavorable electrostatic interactions. Finally, (iii) comparison of these results with those reported previously ${ }^{5}$ indicates that the ability of $\mathrm{Ac}_{\mathrm{n}} \mathrm{c}$ constrained amino acids to adapt their folded conformations within the targeted position improves with the size of the ring. The rigidity introduced by the strain energy of the cyclopropane ring makes this adaptation process more difficult for $\mathrm{Ac}_{3} \mathrm{c}$-mutants than for $\mathrm{Ac}_{6} \mathrm{c}$-mutants.

\section{Supplementary Material}

Refer to Web version on PubMed Central for supplementary material.

\section{Acknowledgments}

Computer resources were generously provided by the Barcelona Supercomputer Center (BSC) and, partially, by Centre de Supercomputació de Catalunya (CESCA). We also acknowledge the National Cancer Institute for partial allocation of computing time and staff support at the Advanced Biomedical Computing Center of the Frederick Cancer Research and Development Center. Classic calculations were partially formed by utilizing the high-performance computational capabilities of the Biowulf PC/Linux cluster at the National Institutes of Health, Bethesda, Md (http://biowulf.nih.gov). DZ thanks financial support from the Ramon y Cajal program of the Spanish "Ministerio de Educación y Ciencia" (MEC). FRR acknowledges financial support from MEC. This project has been funded in whole or in part with Federal funds from the National Cancer Institute, National Institutes of Health, under contract number N01-CO-12400. The content of this publication does not necessarily reflect the view of the policies of the Department of Health and Human Services, nor does mention of trade names, commercial products, or organization imply 
endorsement by the U.S. Government. This research was supported [in part] by the Intramural Research Program of the NIH, National Cancer Institute, Center for Cancer Research.

\section{References}

1. Alemán C, Jiménez AI, Cativiela C, Pérez JJ, Casanovas J. Influence of the Phenyl Side Chain on the Conformation of Cyclopropane Analogues of Phenylalanine. J. Phys. Chem. B 2002;106:1184911858.

2. Casanovas J, Zanuy D, Nussinov R, Alemán C. Identification of the Intrinsic Conformational Properties of 1-Aminocyclobutane-1-Carboxylic Acid. Chem. Phys. Lett 2006;429:558-562.

3. Alemán C, Zanuy D, Casanovas J, Cativiela C, Nussinov R. Backbone Conformational Preferences and Pseudorotational Ring Puckering of 1-Aminocyclopentane-1-Carboxylic Acid. J. Phys. Chem. B 2006;110:21264-21271. [PubMed: 17048955]

4. Alemán C, Zanuy D, Jiménez AI, Cativiela C, Haspel N, Zheng J, Casanovas J, Wolfson H, Nussinov R. Concepts and Schemes for the Re-engineering of Physical Protein Modules: Generating Nanodevices Via Targeted Replacements with Constrained Amino Acids. Phys. Biol 2006;3:S54-S62. [PubMed: 16582465]

5. Zheng J, Zanuy D, Haspel N, Tsai C-J, Alemán C, Nussinov R. Nanostructure Design Using Protein Building Blocks Enhanced by Conformationally Constrained Synthetic Residues. Biochemistry 2007;46:1205-1218. [PubMed: 17260950]

6. Zanuy D, Jiménez AI, Cativiela C, Nussinov R, Alemán C. Use of Constrained Synthetic Amino Acids in $\beta$-Helix Proteins for Conformational Control. J. Phys. Chem. B 2007;111:3236-3242. [PubMed: 17388467]

7. Bardi R, Piazzesi AM, Toniolo C, Sukumar M, Raj P, Balaram P. Conformations of Peptides Containing 1-Aminocylohexane-Carboxilic Acid (ACC6) - Crystal-Structures of 2 Model Peptides. Int. J. Pepti. Protein Res 1985;25:628-639.

8. Paul PKC, Sukumar M, Bardi R, Piazzesi AM, Valle G, Toniolo C, Balaram P. Stereochemically constrained peptides - Theoretical and Experimental Studies on the Conformations of Peptides Containing 1-Aminocyclohexanecarboxylic Acid. J. Am. Chem. Soc 1986;108:6363-6370.

9. Pavone V, Benedetti E, Barone V, Di Blasio B, Lelj F, Pedone C, Santini C, Crisma M, Bonora GM, Toniolo C. Linear Oligopeptides .177. Structural Versatility of Peptides from C- $\alpha$ - $\alpha$-Dialkylated Glycines - A Conformational Energy Computation and X-Ray-Diffraction Study of Homopeptides from 1-Aminocyclohexane-1-Carboxylic Acid. Macromolecules 1988;21:2064-2071.

10. Fabiano N, Valle G, Crisma M, Toniolo C, Saviano M, Lombardi A, Isernia C, Pavone V, Di Blasio B, Pedone C, Benedetti E. Conformational Versatility of the N-Alpha-Acylated Tripeptide Amide Tail of Oxytocin - Synthesis and Crystallographic Characterization of 3 C-2( $\alpha$ )-Backbone Modified, Conformationally Restricted Analogs. Int. J. Pept. Protein Res 1993;42:459-465. [PubMed: 8106198]

11. Crisma M, Bonora GM, Toniolo C, Bavoso A, Benedetti E, Di Blasio V, Pavone C, Pedone C. Linear Oligopeptides .178. Structural Versatility of Peptides from C- $\alpha$ - $\alpha$-Dialkylated Glycines - An Infrared-Absorption and $\mathrm{H}^{1}$ Nuclear Magnetic-Resonance Study of Homopeptides from 1Aminocyclohexane-1-Carboxilic Acid. Macromolecules 1988;21:2071-2074.

12. Saviano M, Isernia C, Rossi F, Di Blasio B, Iacovino R, Mazzeo M, Pedone C, Bendetti E. Solid State Structural Analysis of the Cyclooctapeptide Cyclo-(Pro(1)-Pro-Phe-Phe-Ac(6)c-Ile-D-Ala-Val(8)). Biopolymers 2000;53:189-199. [PubMed: 10679623]

13. Dawidowska O, Wierzba TH, Prahl A, Kowalczyk W, Gawinski L, Plackova M, Slaninova J, Lammerk B. New Bradykinin Analogues Modified in the C-Terminal Part with Sterically Restricted 1-Aminocyclohexane-1-carboxylic Acid. J. Med. Chem 2005;48:8055-8059. [PubMed: 16335929]

14. Kowalczyk W, Prahl A, Derdowska I, Dawidowska O, Slaninova J, Lammek B. Highly Potent 1Aminocyclohexane-1-Carboxylic Acid Substituted V2 Agonists of Arginine Vasopressin. J. Med. Chem 2004;47:6020-6024. [PubMed: 15537356]

15. Haspel N, Zanuy D, Alemán C, Wolfson H, Nussinov R. De Novo Tubular Nanostructure Design Based on Self-Assembly of $\beta$-Helical Protein Motifs. Structure 2006;14:1137-1148. [PubMed: 16843895] 
16. Frisch, MJ.; Trucks, GW.; Schlegel, HB.; Scuseria, GE.; Robb, MA.; Cheeseman, JR.; Montgomery, JA.; Vreven, T., Jr; Kudin, KN.; Burant, JC.; Millam, JM.; Iyengar, SS.; Tomasi, J.; Barone, V.; Mennucci, B.; Cossi, M.; Scalmani, G.; Rega, N.; Petersson, GA.; Nakatsuji, H.; Hada, M.; Ehara, M.; Toyota, K.; Fukuda, R.; Hasegawa, J.; Ishida, M.; Nakajima, T.; Honda, Y.; Kitao, O.; Nakai, H.; Klene, M.; Li, X.; Knox, JE.; Hratchian, HP.; Cross, JB.; Adamo, C.; Jaramillo, J.; Gomperts, R.; Stratmann, RE.; Yazyev, O.; Austin, AJ.; Cammi, R.; Pomelli, C.; Ochterski, JW.; Ayala, PY.; Morokuma, K.; Voth, GA.; Salvador, P.; Dannenberg, JJ.; Zakrzewski, VG.; Dapprich, S.; Daniels, ADC.; Strain, M.; Farkas, O.; Malick, DK.; Rabuck, AD.; Raghavachari, K.; Foresman, JB.; Ortiz, JV.; Cui, Q.; Baboul, AG.; Clifford, S.; Cioslowski, J.; Stefanov, BB.; Liu, G.; Liashenko, A.; Piskorz, P.; Komaromi, I.; Martin, RL.; Fox, DJ.; Keith, T.; Al-Laham, MA.; Peng, CY.; Nanayakkara, A.; Challacombe, M.; Gill, PMW.; Johnson, B.; Chen, W.; Wong, MW.; Gonzalez, C.; Pople, JA. Gaussian 03. Revision B.02. Pittsburgh PA: Gaussian, Inc.; 2003.

17. Alemán C, Casanovas J, Hall HK Jr. Systematic Evaluation of the Conformational Properties of Aliphatic $\omega$-Methoxy Methyl Esters. J. Org. Chem 2005;70:7731-7736. [PubMed: 16149806]

18. Becke AD. A New Mixing of Hartree-Fock and Local Density-Functional Theories. J. Chem. Phys 1993;98:1372-1377.

19. Lee C, Yang W, Parr RG. Development of the Colle-Salvetti Correlation-Energy Formula Into a Functional of the Electron Density. Phys. Rev. B 1993;37:785-789.

20. McLean AD, Chandler GS. Contracted Gaussian Basis Sets for Molecular Calculations. I. Second Row Atoms, Z=11-18. J. Chem. Phys 1980;72:5639-5648.

21. Miertus M, Scrocco E, Tomasi J. Electrostatic Interaction of a Solute with a Continuum - A Direct Utilization of Ab Initio Molecular Potentials for the Prevision of Solvent Effects. Chem. Phys 1981;55:117-129.

22. (a) Tomasi J, Persico M. Molecular-Interactions in Solution - An Overview of Methods Based on Continuous Distributions of the Solvent. Chem. Rev 1994;94:2027-2094. (b) Tomasi J, Mennucci B, Cammi R. Quantum Mechanical Continuum Solvation Models. Chem. Rev 2005;105:2999-3093. [PubMed: 16092826]

23. Phillips JC, Braun R, Wang W, Gumbart J, Tajkhorshid E, Villa E, Chipot C, Skeel RD, Kale L, Schulten K. Scalable Molecular Dynamics with NAMD. J. Comput. Chem 2005;26:1781-1802. [PubMed: 16222654]

24. Jorgensen WL, Chandrasekhar J, Madura JD, Impey RW, Klein ML. Comparison of Simple Potential Functions for Simulating Liquid Water. J. Chem. Phys 1983;79:926-935.

25. Wang J, Cieplak P, Kollman PA. How Well Does a Restrained Electrostatic Potential (RESP) Model Perform in Calculating Conformational Energies of Organic and Biological Molecules? J. Comput. Chem 2000;21:1049-1074.

26. Cornell WD, Cieplak P, Bayly CI, Gould IR, Merz KM, Ferguson DM, Spellmeyer DC, Fox T, Caldwell JW, Kollman PA. A Second Generation Force Field for the Simulation of Proteins, Nucleic Acids, and Organic Molecules. J. Am. Chem. Soc 1995;117:5179-5197.

27. Darden T, York D, Pedersen L. Particle mesh Ewald: An N·log(N) Method for Ewald Sums in Large Systems. J. Chem. Phys 1993;98:10089-10092.

28. Ryckaert JP, Ciccotti G, Berendsen HJC. Numerical-Integration of Cartesian Equations of Motion of a System with Constraints - Molecular-Dynamics of N-Alkanes. J. Comput. Phys 1977;23:327-341.

29. Berendsen HJC, Postma JPM, van Gunsteren WF, DiNola A, Haak JR. Molecular Dynamics with Coupling to an External Bath. J. Chem. Phys 1984;81:3684-3690. 


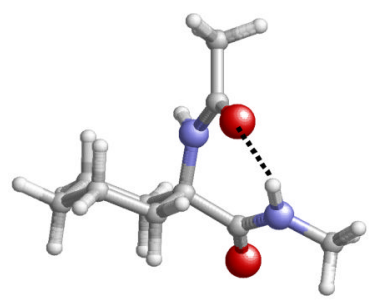

I

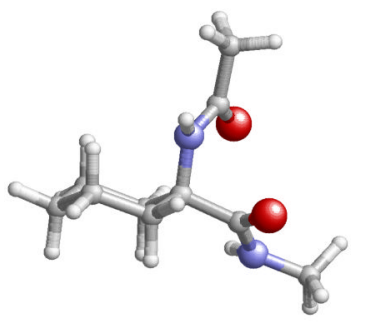

IV

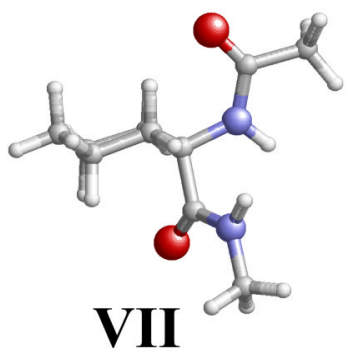

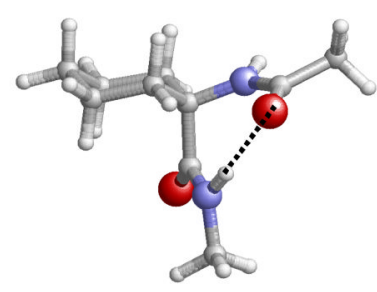

II

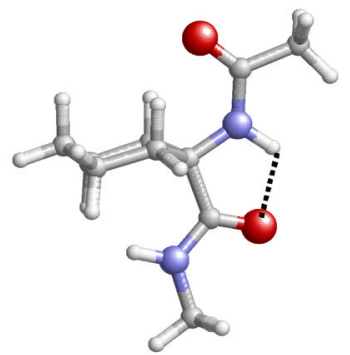

V

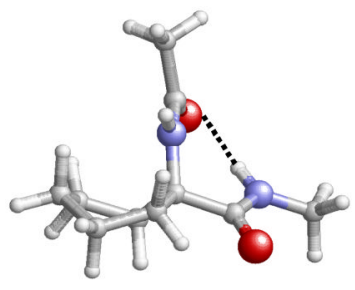

VIII

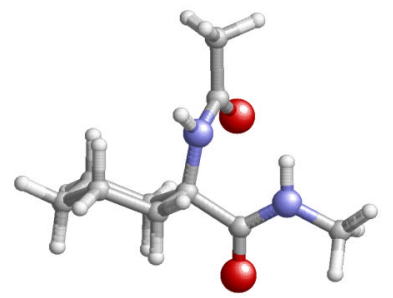

III

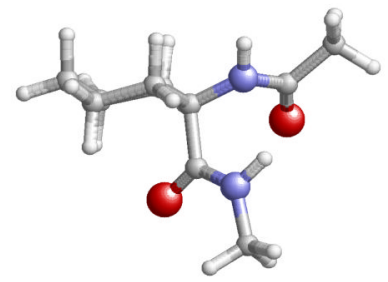

IX

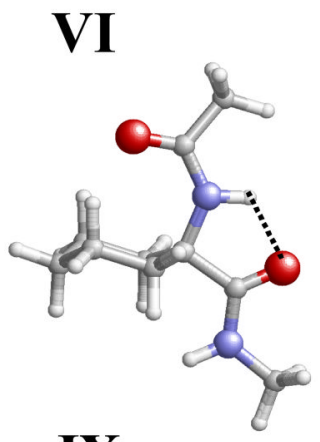

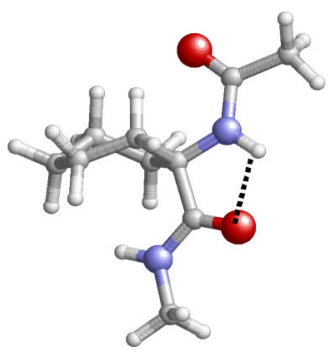

$\mathbf{X}$

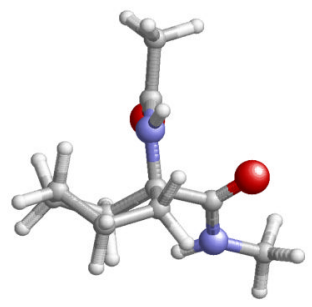

XI

Figure 1.

Molecular structure of the minimum energy conformations characterized for the $A c-A_{6} \mathrm{c}-$ NHMe dipeptide at the B3LYP/6-31+G(d,p) level. Intramolecular hydrogen bonds are indicated by dashed lines. The structural characteristics of each minimum are described in Table 1. 


\section{Gas-phase}
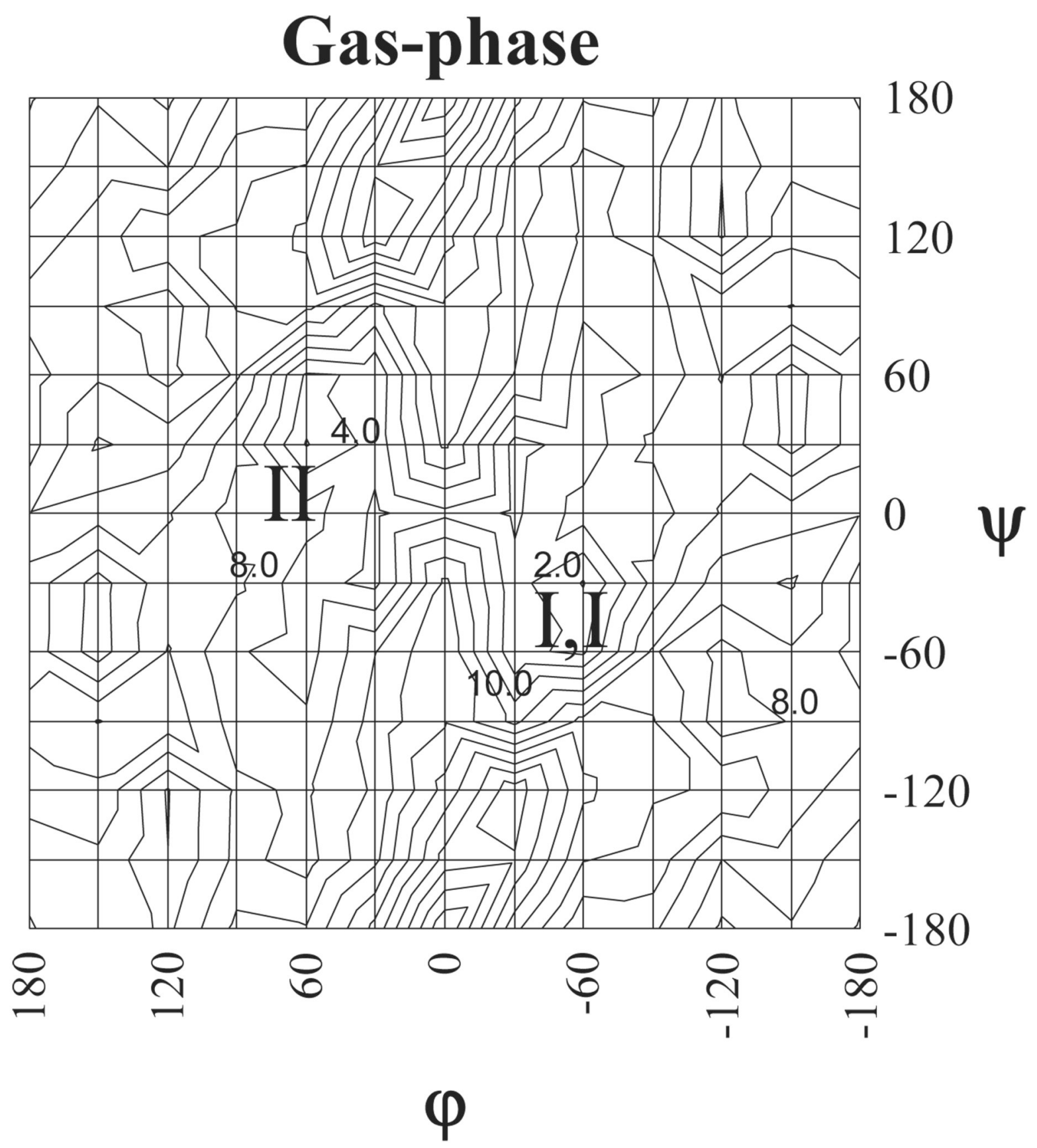

Figure 2.

Ramachandran map of the Ac-Ac ${ }_{6} \mathrm{c}-\mathrm{NHMe}$ dipeptide in gas-phase computed at the B3LYP/ $6-31+\mathrm{G}(\mathrm{d}, \mathrm{p})$ level of theory. Energies (in $\mathrm{kcal} / \mathrm{mol}$ ) are relative to the lowest energy minimum. Contours are drawn every two kilocalories per mole. The position of the minima with lower free energies (see Table 2) is indicated. 
Chloroform

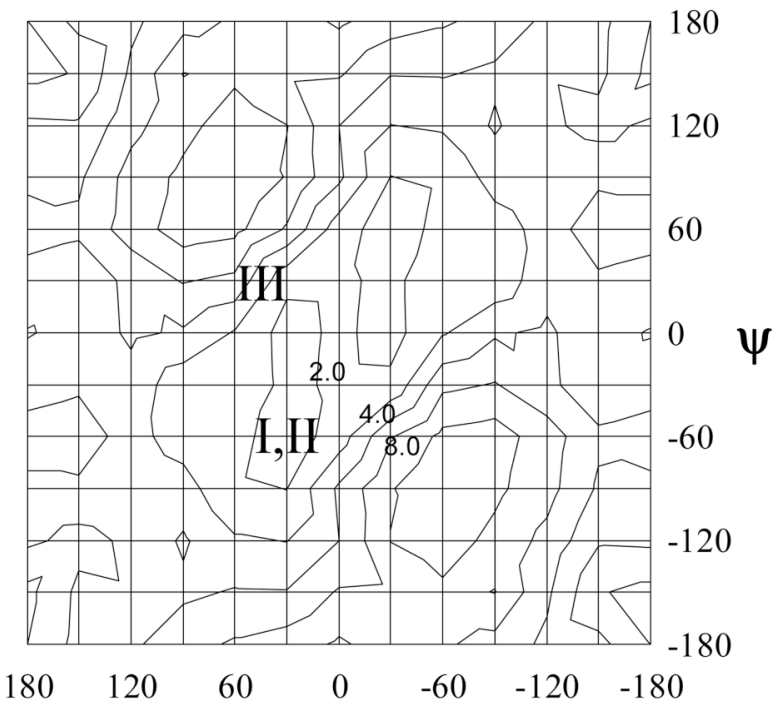

$\varphi$
Methanol

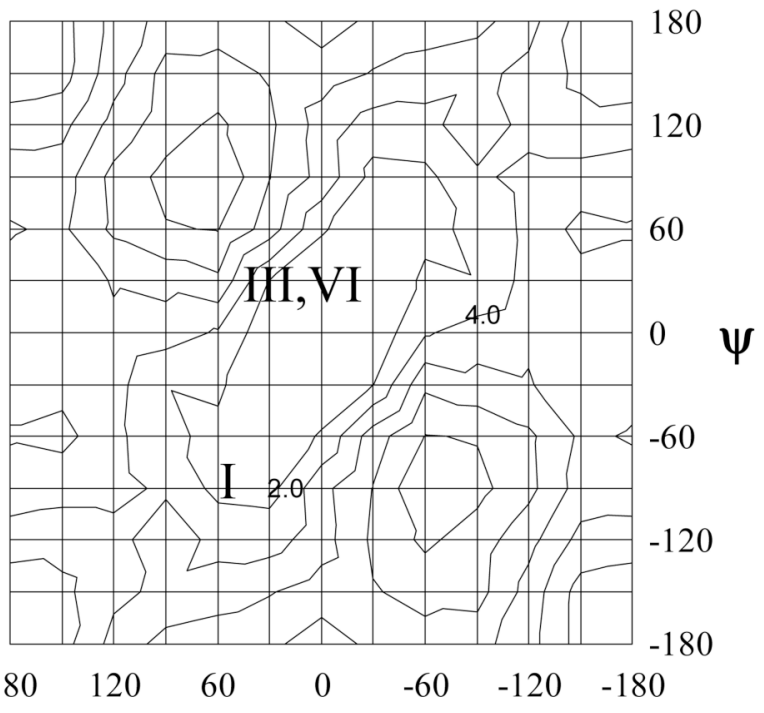

$\varphi$

\section{Water}

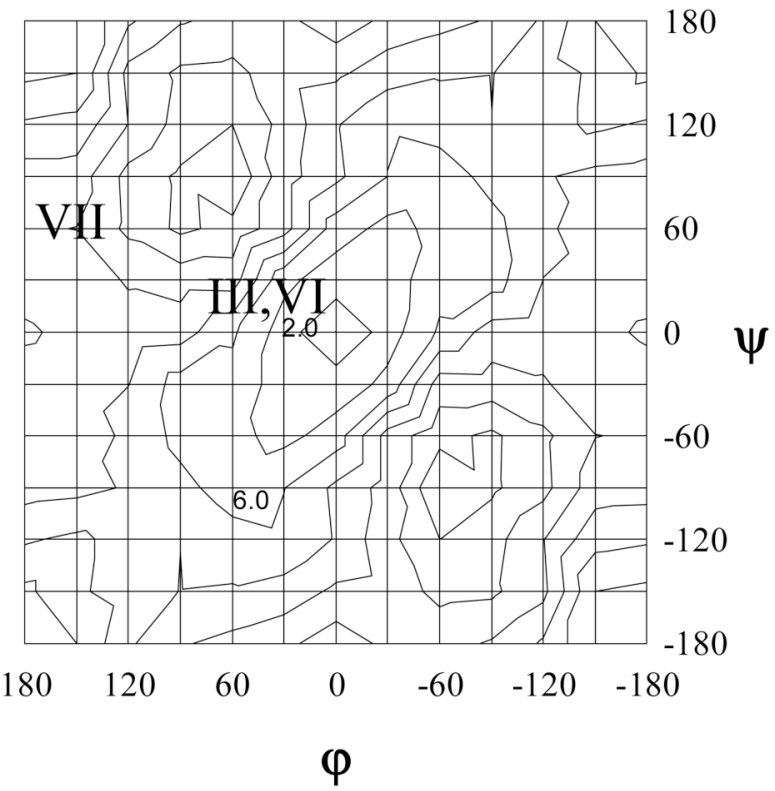

Figure 3.

Ramachandran maps of the Ac-Ac $\mathrm{Ac}_{6} \mathrm{-NHMe}$ dipeptide in chloroform, methanol and water solutions computed at the B3LYP/6-31+G(d,p) level of theory. Energies (in $\mathrm{kcal} / \mathrm{mol}$ ) are relative to the lowest energy minimum. Contours are drawn every two kilocalories per mole. The position of the minima with lower free energies (see Table 2) is indicated in each case. 


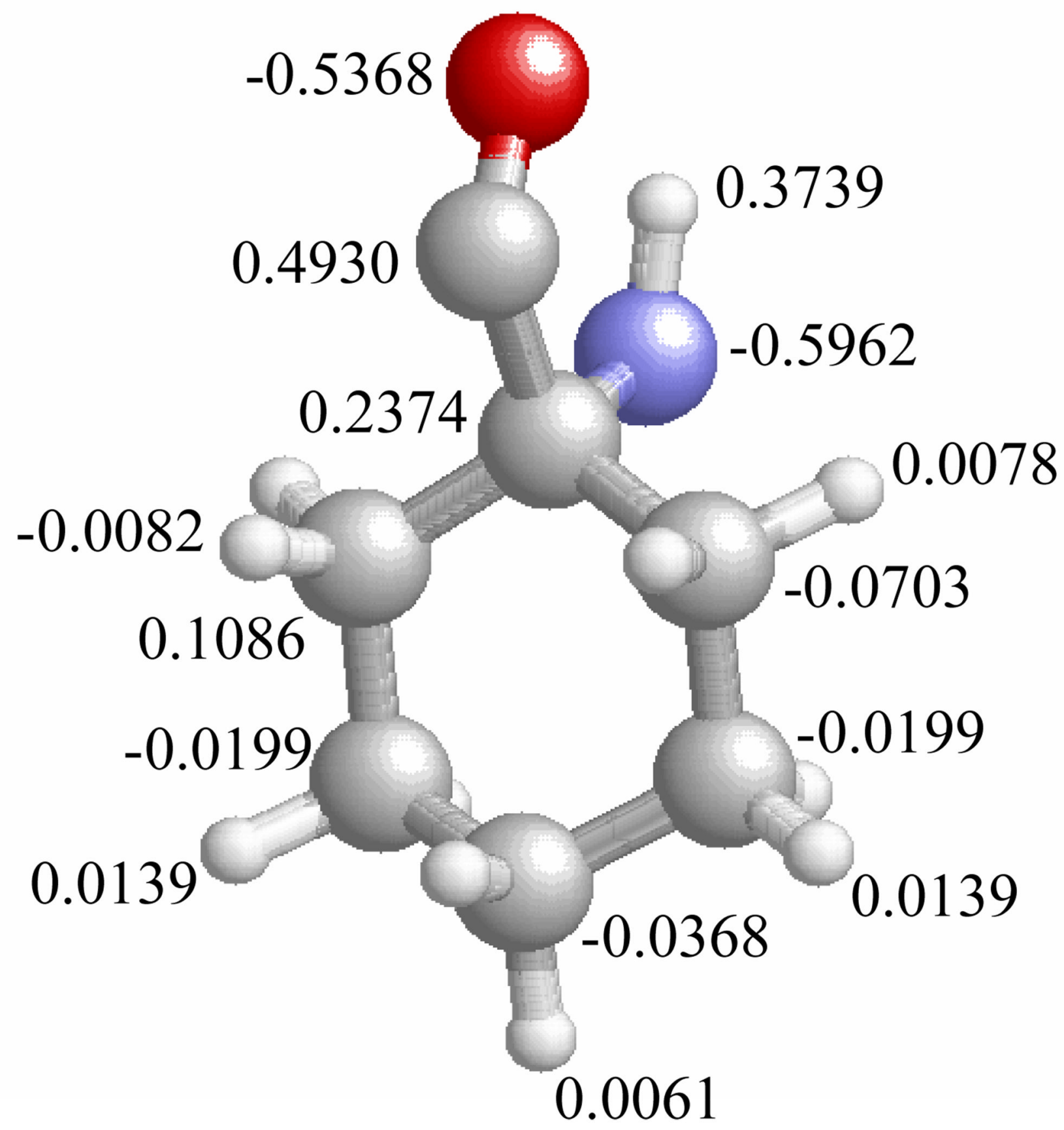

Figure 4.

Electrostatic parameters determined for the $\mathrm{Ac}_{6} \mathrm{c}$ residue. 


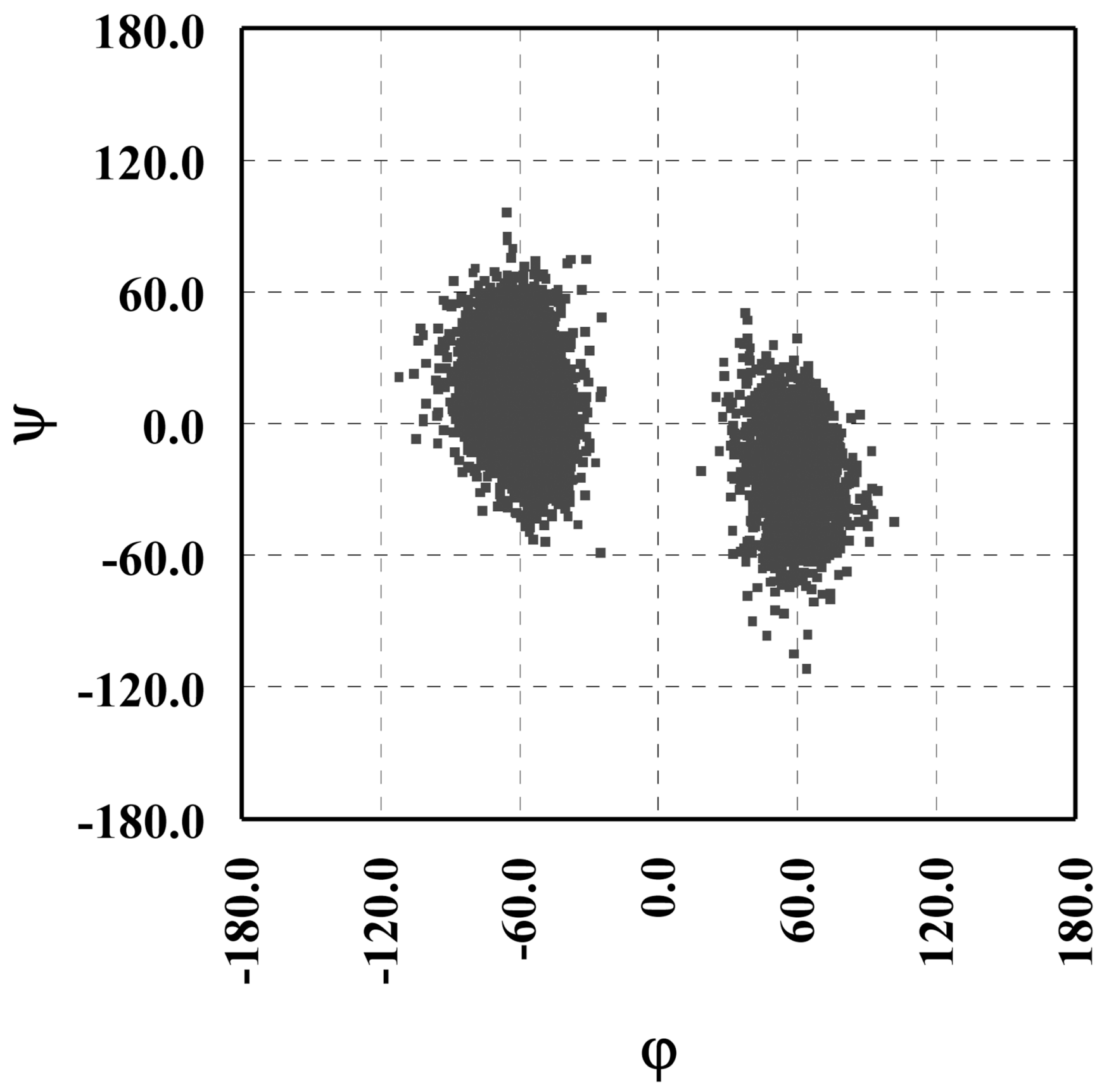

Figure 5.

Accumulated Ramachandran plot for $\mathrm{Ac}_{\mathrm{c}}-\mathrm{Ac}_{6} \mathrm{c}-\mathrm{NHMe}$ derived from $\mathrm{MD}$ trajectories in the gasphase. 


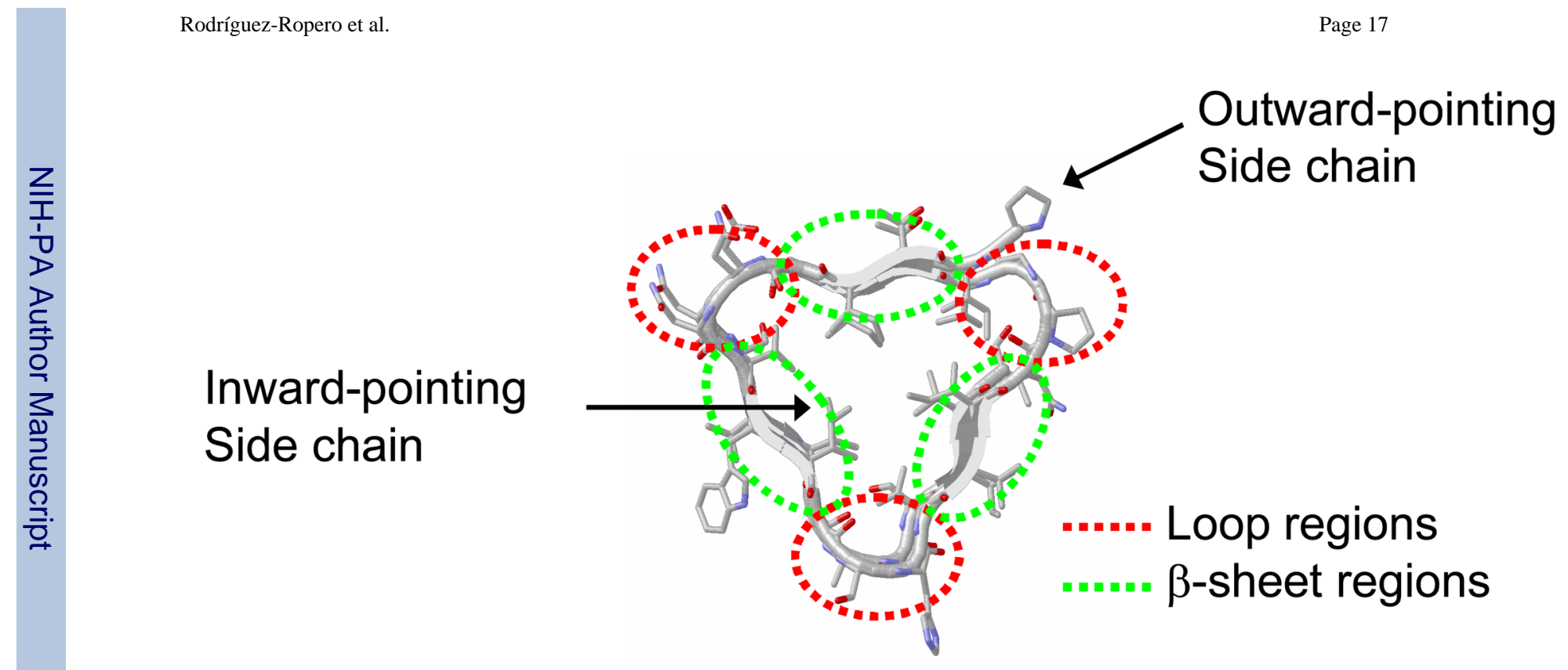

Figure 6.

Schematic picture showing the loop and $\beta$-sheet regions of the $\beta$-helix as well as residues with outward- and inward-pointing side chains. 
(a)

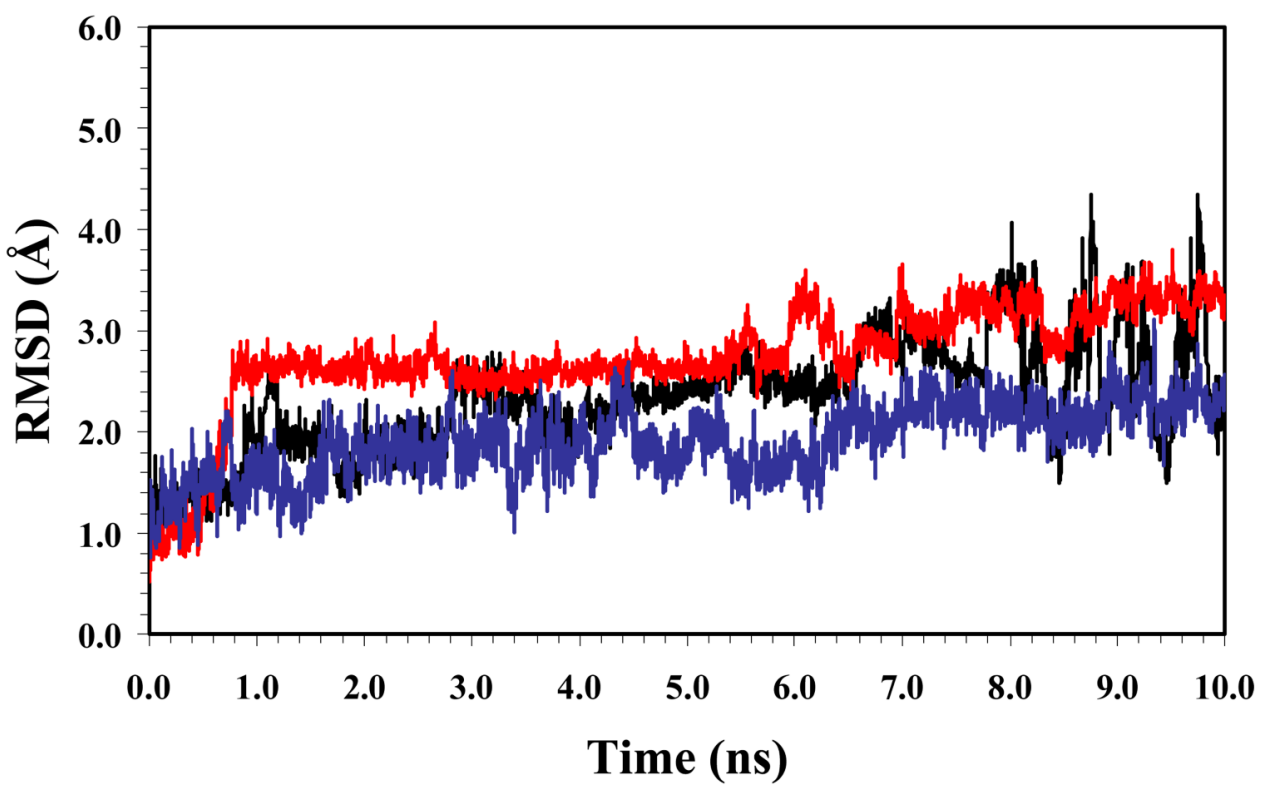

(b)

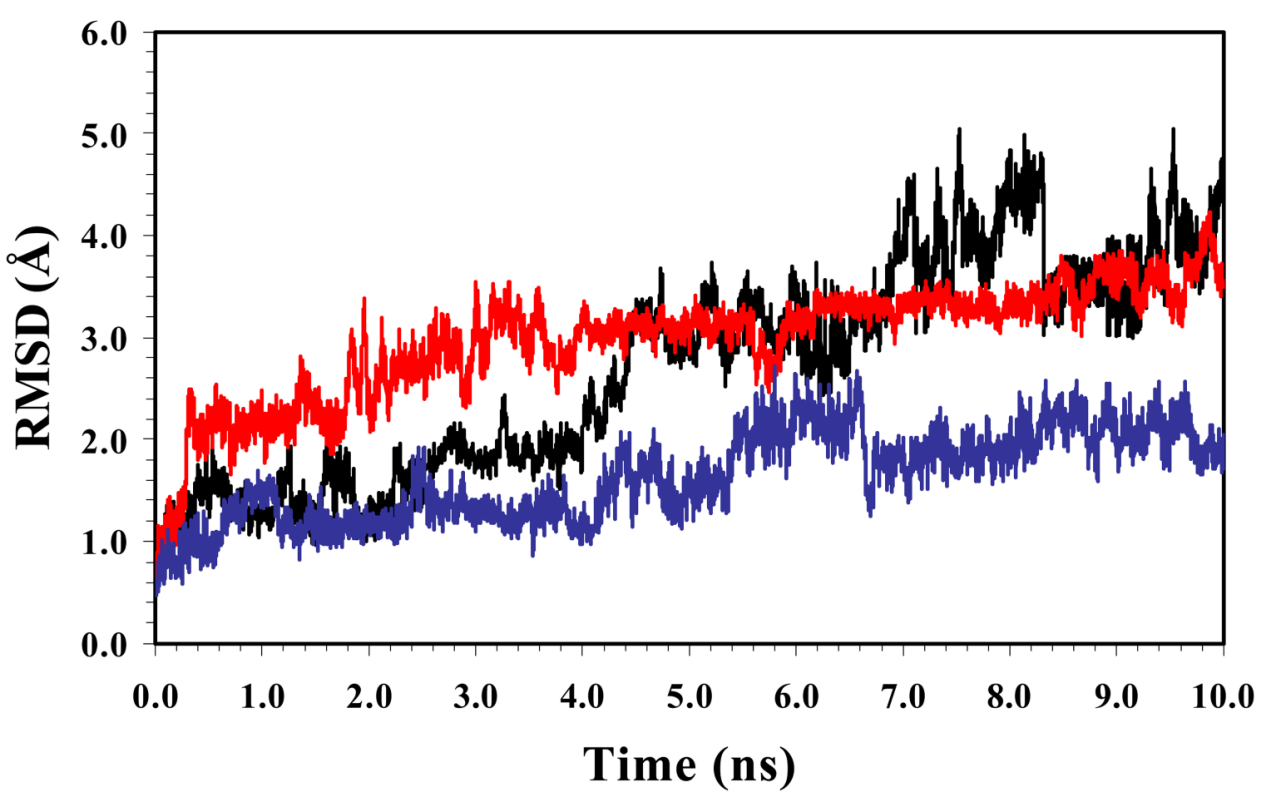

Figure 7.

Comparison of the RMSD (in $\AA$ ) for the wild type and mutated building blocks. (a) Building

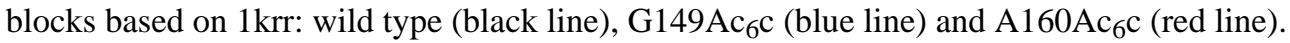
(b) Building blocks based on 1hv9: wild type (black line), D306 $\mathrm{Ac}_{6} \mathrm{c}$ (blue line) and $\mathrm{A} 322 \mathrm{Ac}_{6} \mathrm{c}$ (red line). 


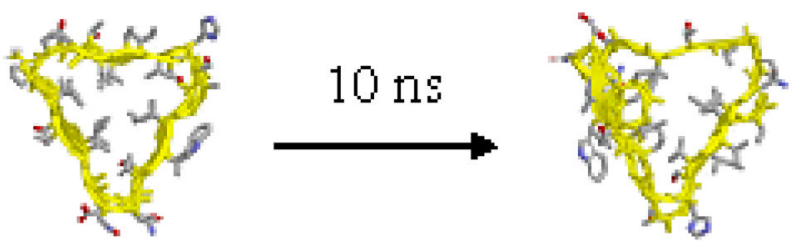

$1 \mathrm{krr}$ wt
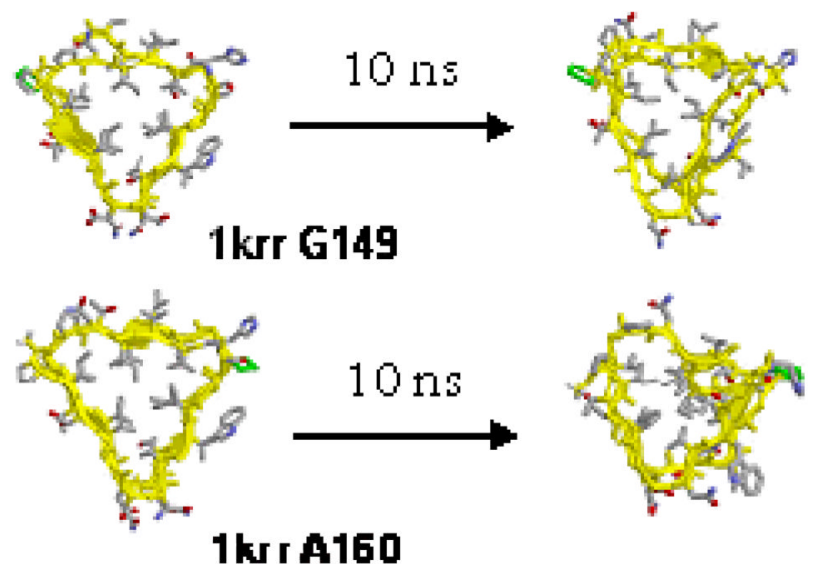

$1 \mathrm{kr}$ r A160

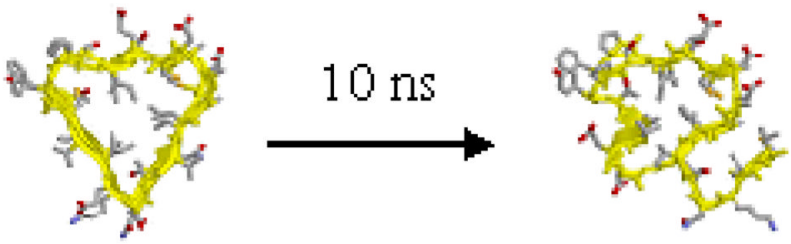

$1 \mathrm{~h} 92 \mathrm{wt}$

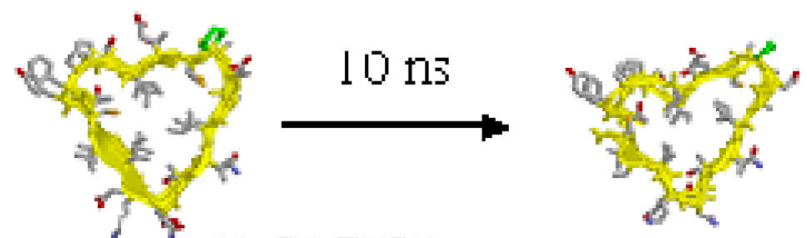

$1 \operatorname{ma2} 0306$
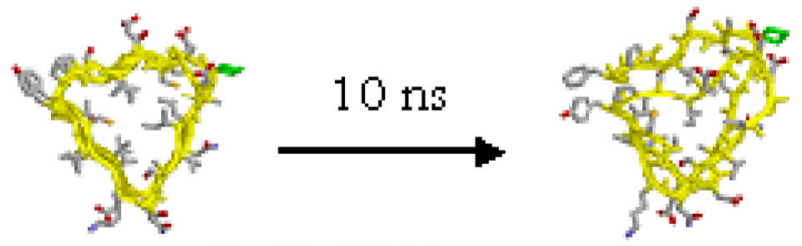

$1 \ln 92 \mathrm{A322}$

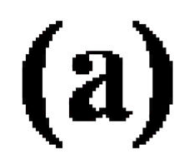

(b)

Figure 8.

Structure of the wild type and mutated building blocks of $1 \mathrm{krr}$ (a) and 1hv9 (b) after $10 \mathrm{~ns}$ of MD simulation. The hydrogen atoms have been omitted for clarity and the backbone has been represented by solid shapes (arrows indicate sheet conformation). 
(a)

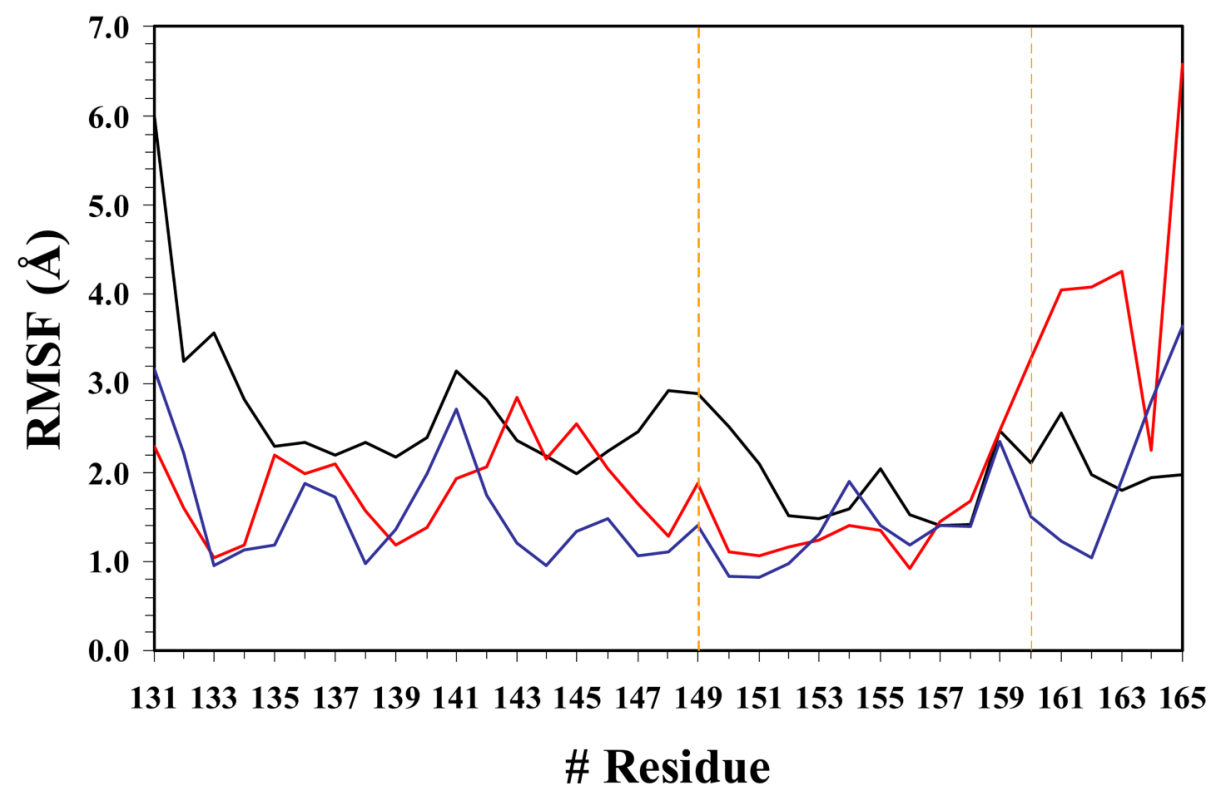

(b)

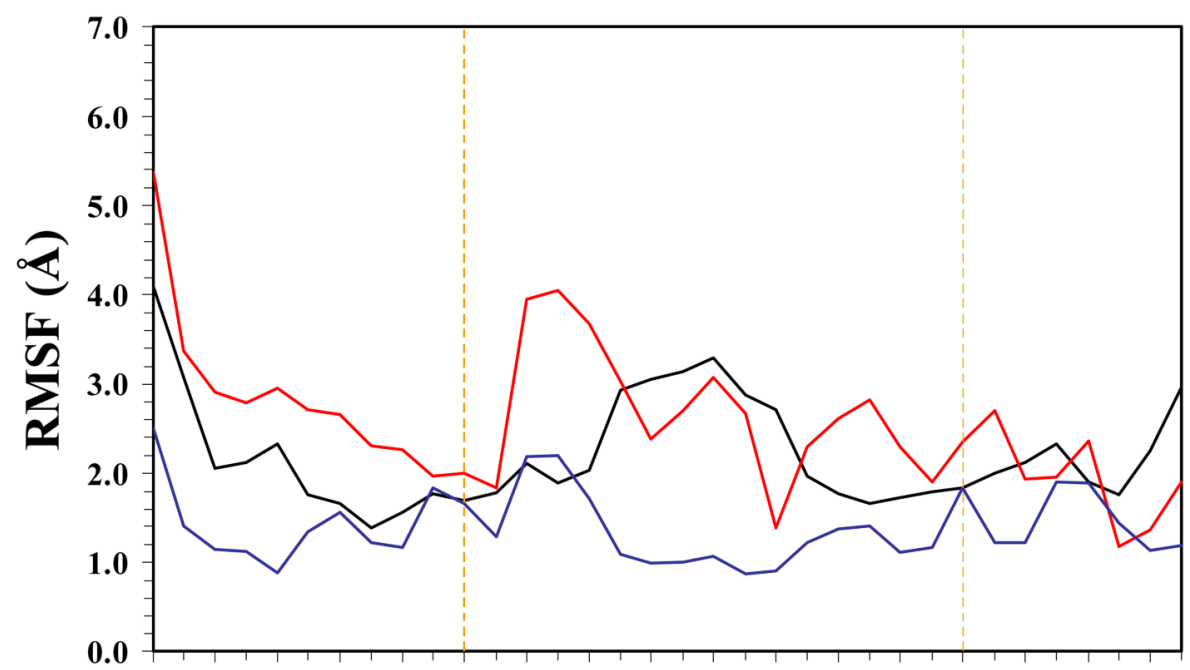

296298300302304306308310312314316318320322324326328

\# Residue

Figure 9.

Comparison of the RMSF for the wild type and mutated building blocks. (a) Building blocks

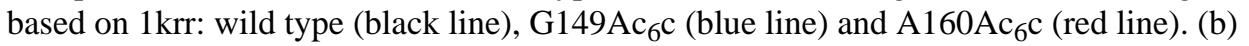
Building blocks based on 1hv9: wild type (black line), D306 $\mathrm{Ac}_{6} \mathrm{c}$ (blue line) and $\mathrm{A} 322 \mathrm{Ac}_{6} \mathrm{c}$ (red line). Yellow dashed lines indicate the position of the substitutions. 


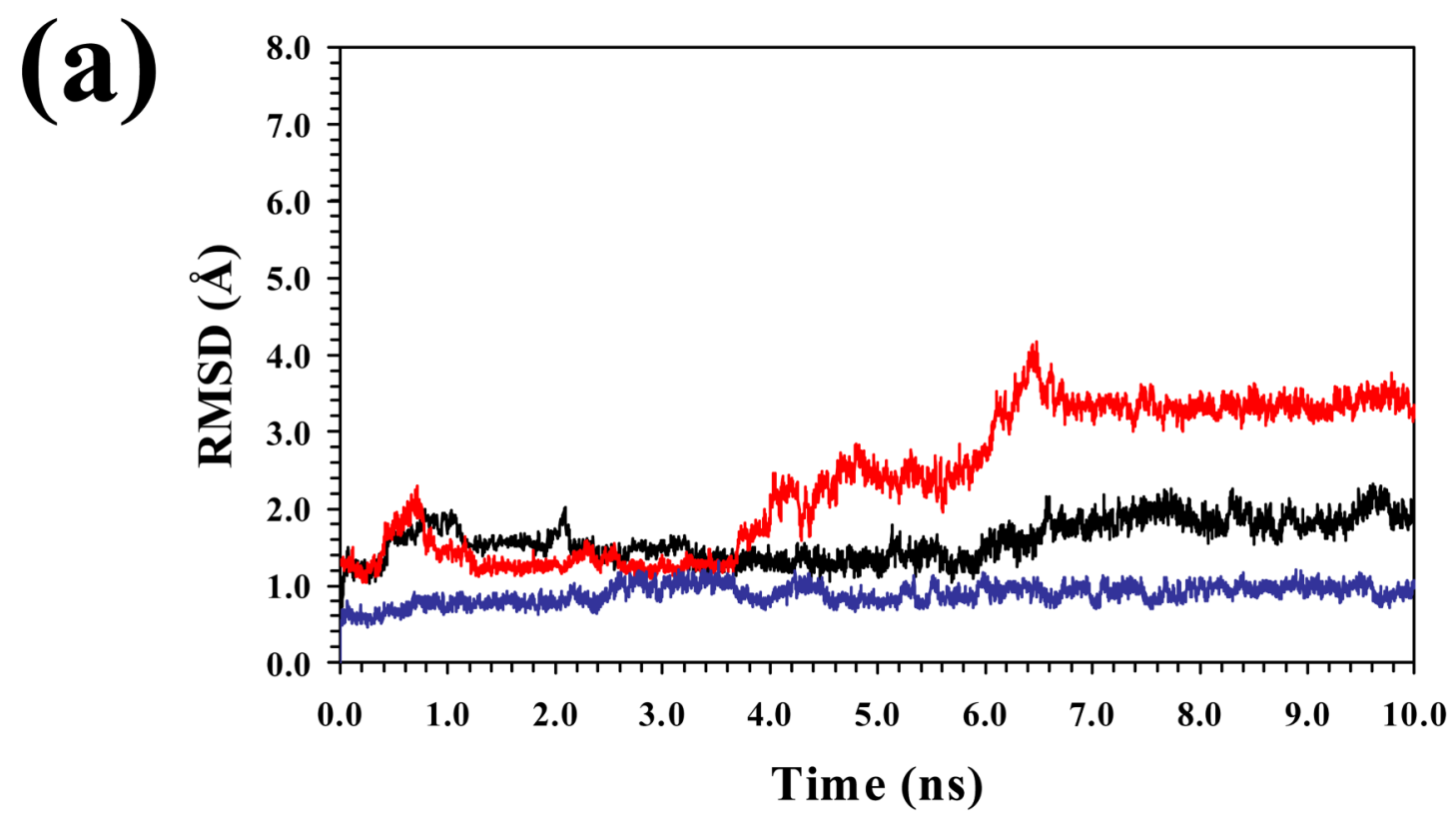

(b)

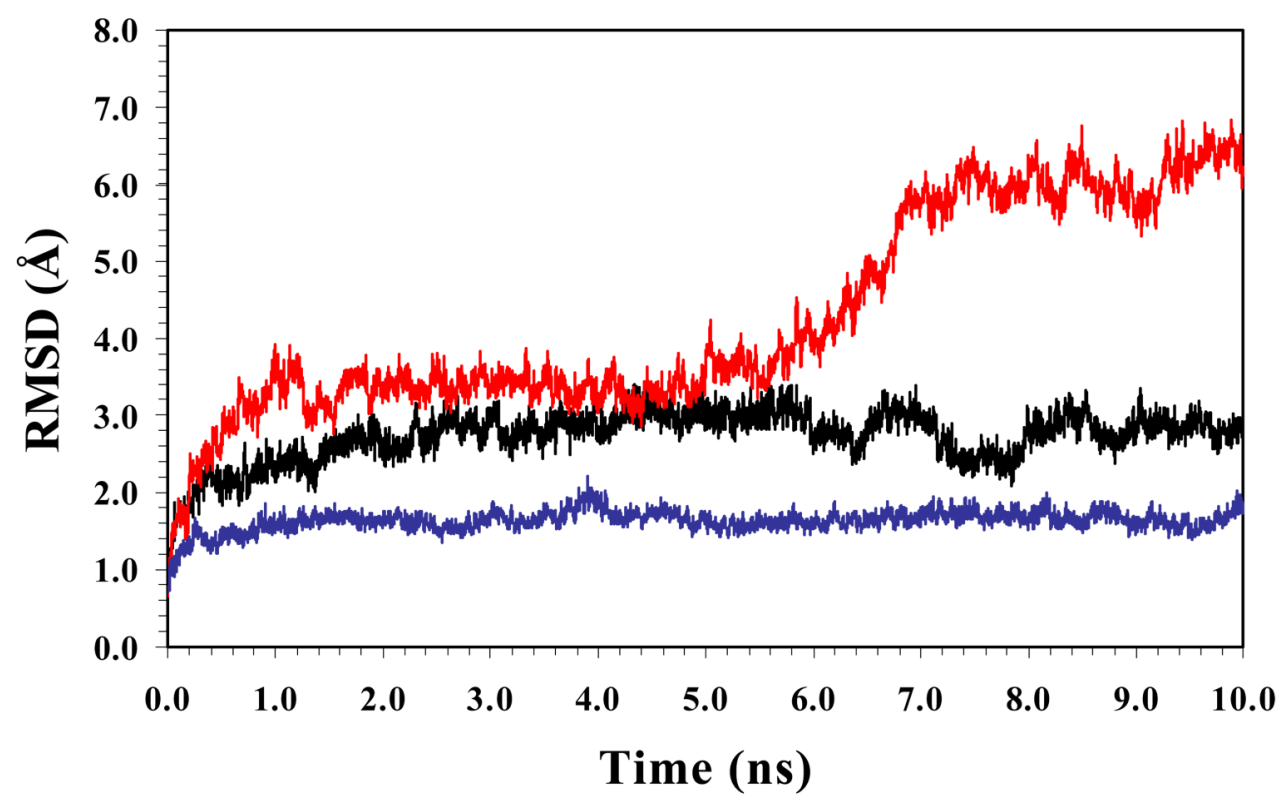

Figure 10.

Evolution of the backbone RMSD (in $\AA$ ) of the simulated nanotube models based on the selfassembly of both wild type and mutated building blocks. (a) Building blocks based on 1krr: wild type (black line), G149Ac 6 c (blue line) and A160Ac 6 c (red line). (b) Building blocks based on 1hv9: wild type (black line), D306Ac 6 c (blue line) and $\mathrm{A} 322 \mathrm{Ac}_{6} \mathrm{c}$ (red line). 

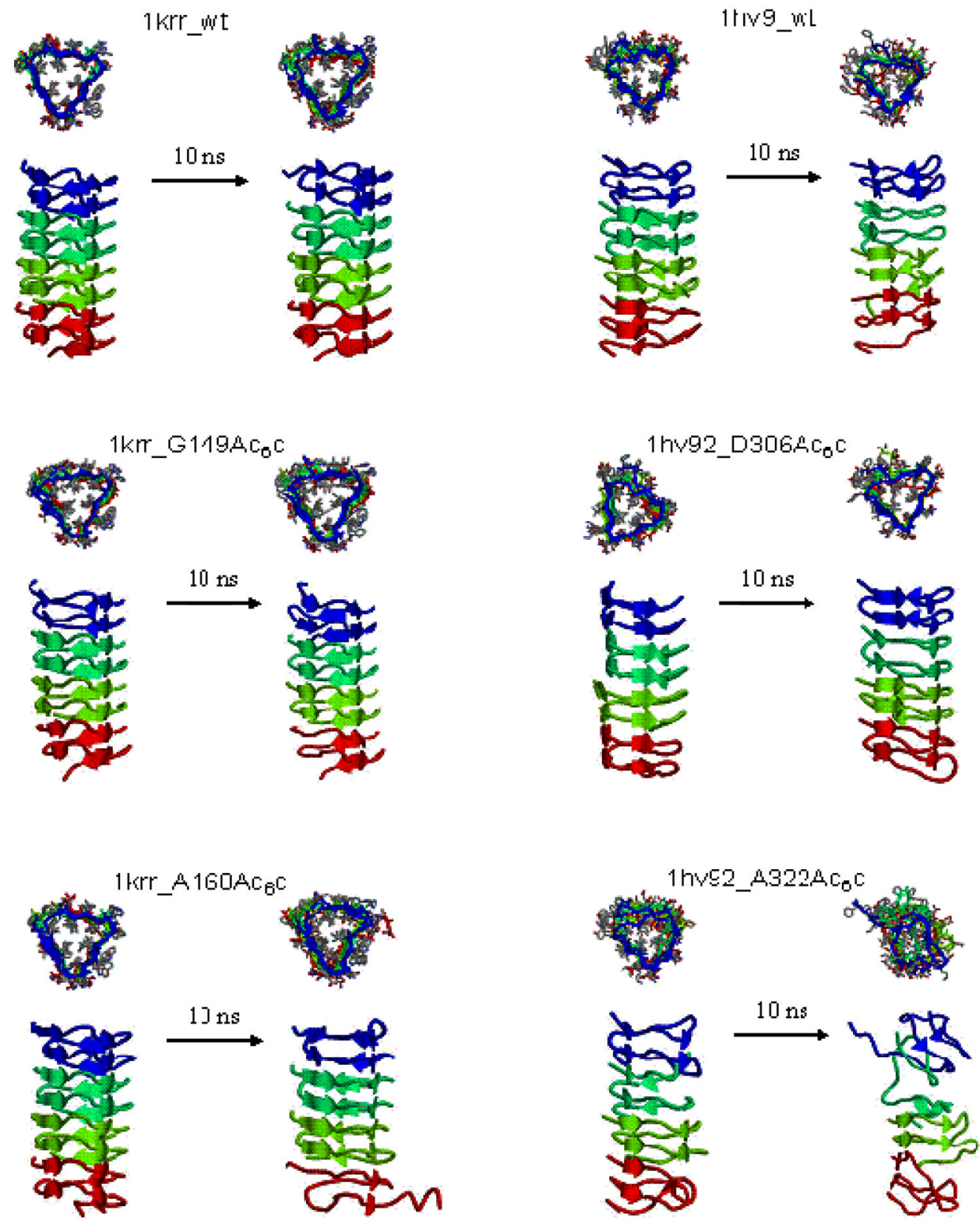

\section{(a)}

(b)

Figure 11.

Structure of the nanotube models based on the self-assembly of wild type and mutated building blocks of $1 \mathrm{krr}$ (a) and $1 \mathrm{hv} 9$ (b) after $10 \mathrm{~ns}$ of MD simulation. The hydrogen atoms have been omitted for clarity and the backbone has been represented by solid shapes (arrows indicate sheet conformation). Stacked $\beta$-helix building blocks have been represented by different colors. 


\section{(a)}

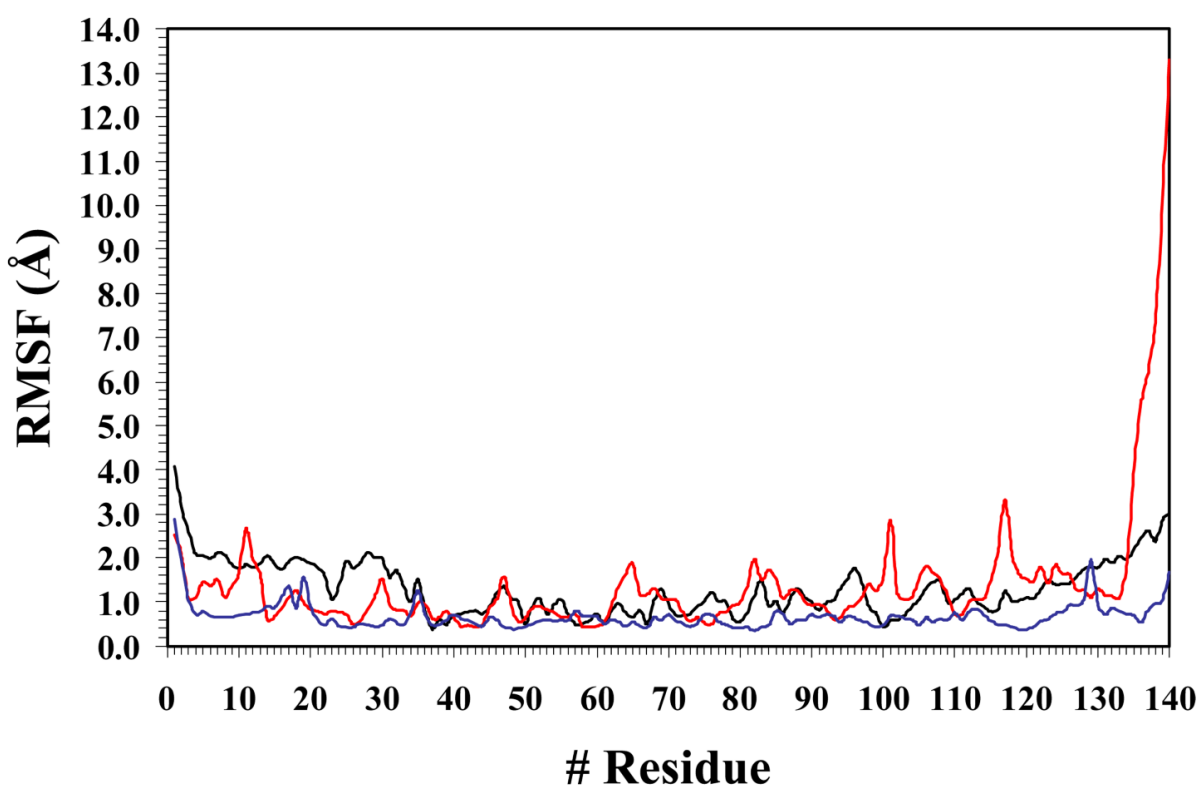

(b)

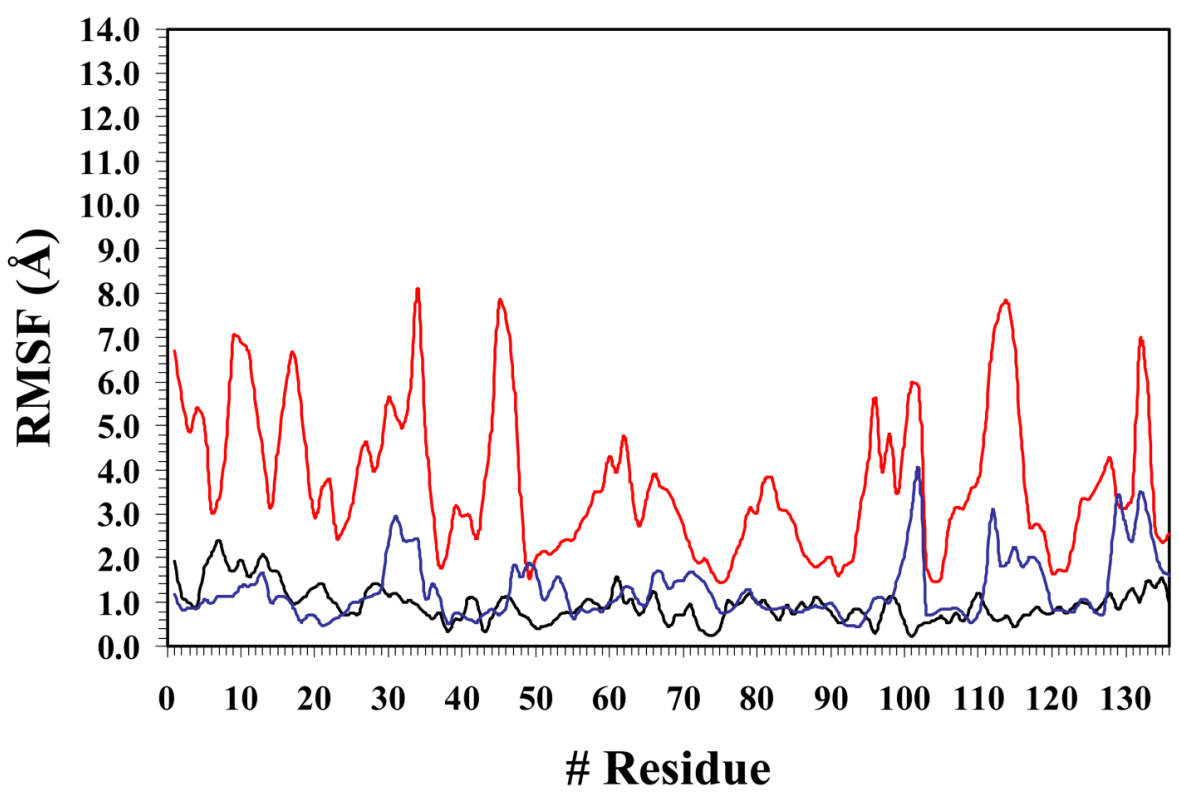

Figure 12.

Comparison of the RMSF for the wild type and mutated sequences in self-assembled nanotubes.

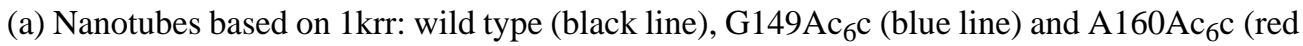
line). (b) Nanotubes based on 1hv9: wild type (black line), D306 $\mathrm{Ac}_{6} \mathrm{c}$ (blue line) and $\mathrm{A} 322 \mathrm{Ac}_{6} \mathrm{c}$ (red line). 


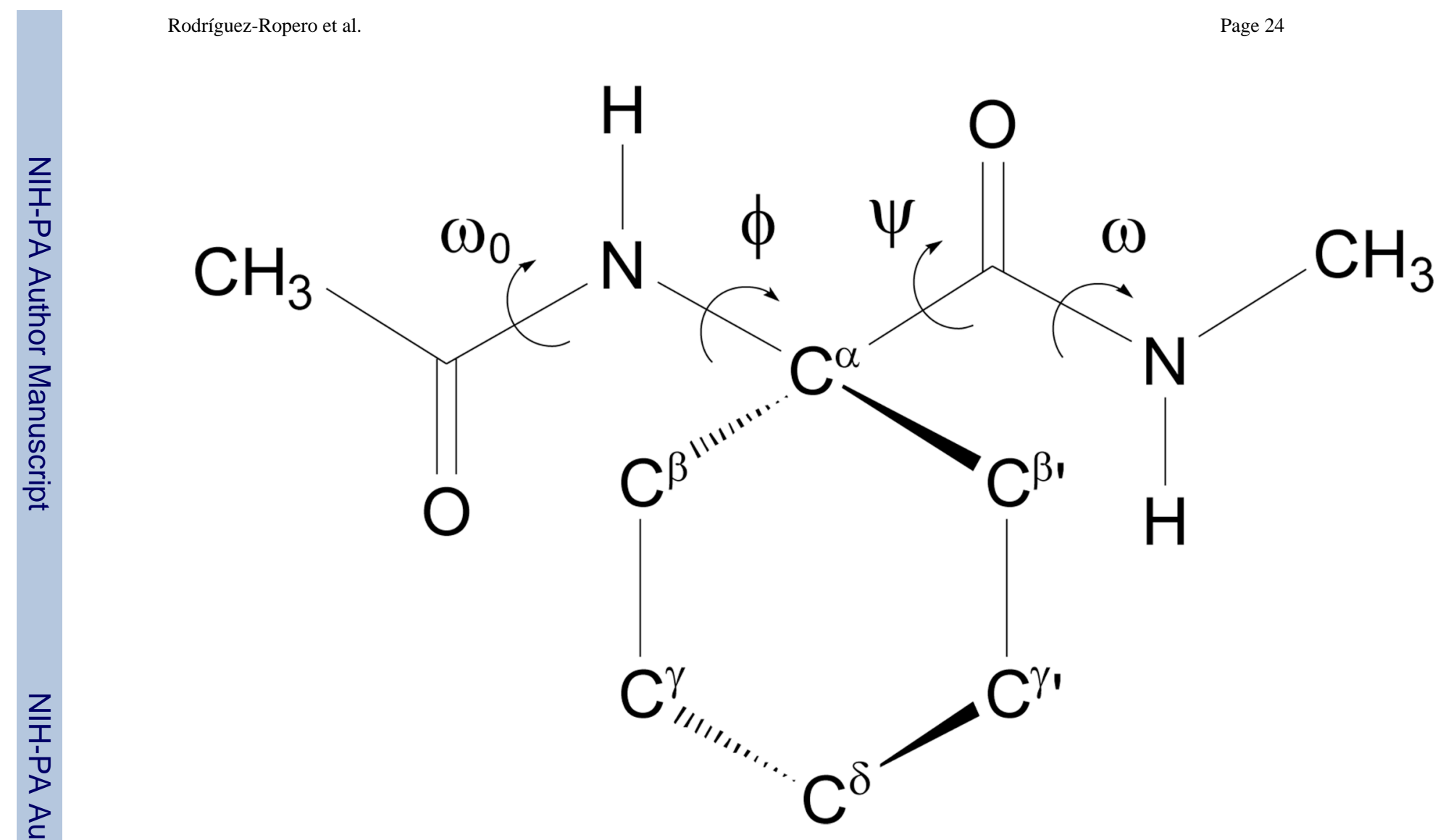

Scheme 1. 

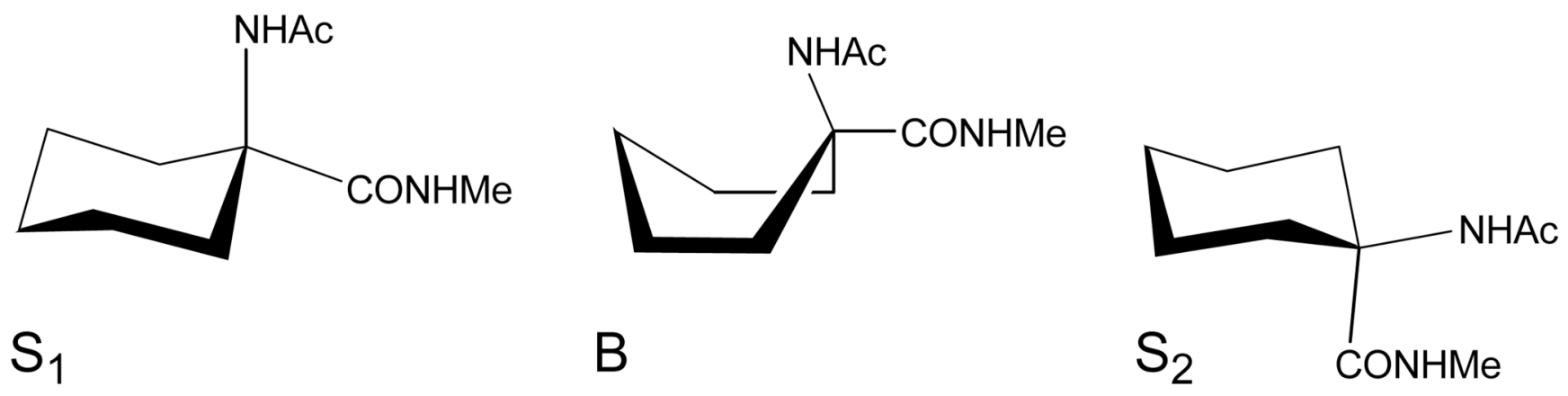

Scheme 2. 


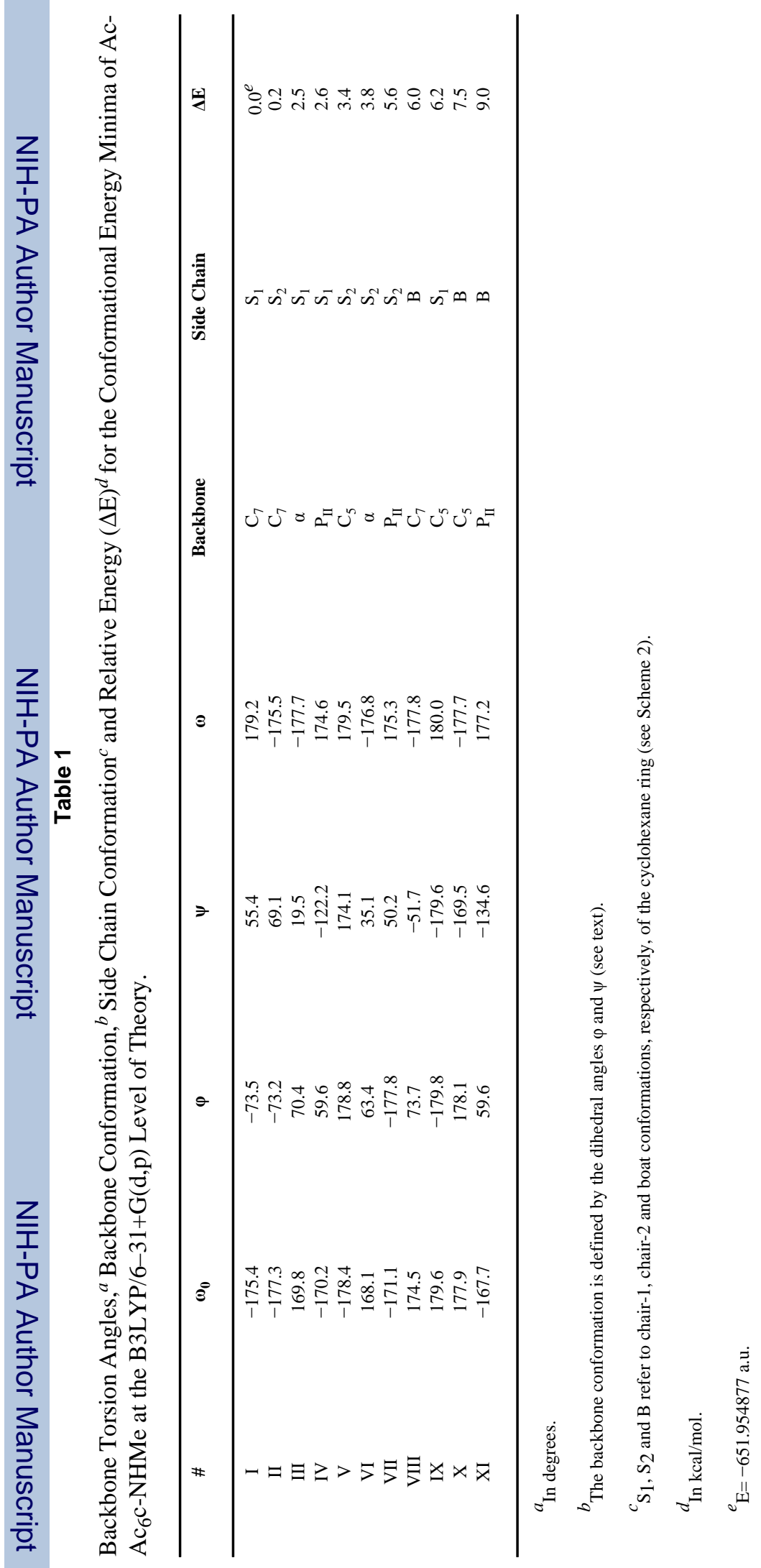


Table 2

Conformational Free Energies in the Gas-phase, Chloroform, Methanol and Aqueous Solutions for the Energy Minima of Ac-Ac $c_{6} c-N H M e$ determined at the B3LYP/6-31+G(d,p) Level of Theory.

\begin{tabular}{ccccc}
\hline$\#$ & $\mathbf{\Delta G}^{\mathbf{g p}}$ & $\mathbf{\Delta G}^{\mathbf{C H C 1 3}}$ & $\mathbf{\Delta G}^{\mathbf{M e O H}}$ & $\mathbf{A G}^{\mathbf{H 2 O}}$ \\
\hline I & $0.0^{a}$ & 0.0 & 1.5 & 1.8 \\
II & 0.6 & 1.1 & 2.4 & 3.1 \\
III & 1.6 & 1.5 & 0.3 & 0.7 \\
IV & 1.8 & 1.5 & 1.7 & 2.1 \\
V & 2.1 & 1.8 & 5.2 & 3.4 \\
VI & 3.5 & 1.8 & 0.0 & 0.0 \\
VII & 4.5 & 3.3 & 3.4 & 3.0 \\
VIII & 5.9 & 4.5 & 3.3 & 3.9 \\
IX & 5.7 & 5.3 & 4.3 & 4.1 \\
X & 7.4 & 5.9 & 4.4 & 4.4 \\
XI & 8.0 & & & \\
\hline
\end{tabular}

${ }^{a} \mathrm{G}=-651.717012$ a.u. 
Table 3

Sequences of the wild type $1 \mathrm{krr}$ and $1 \mathrm{hv} 9$ building blocks used to construct the nanotubes. For each fragment the mutated residues are highlighted with both bolding and italics.

\begin{tabular}{|c|c|c|c|}
\hline PDB & Protein name & Residues & Sequence \\
\hline $1 \mathrm{krr}$ & $\begin{array}{l}\text { Galactoside } \\
\text { acetyltransferase from e. } \\
\text { coli }\end{array}$ & $131-165$ & $\begin{array}{l}\text { PITIGNNVWIGSHVVINP } \\
\boldsymbol{G V T I G D N S V I G A G S I V T}\end{array}$ \\
\hline 1hv9 & $\begin{array}{l}\text { N-acetylglucosamine 1- } \\
\text { phosphate uridyltransferase } \\
\text { GlmU, C-terminal domain } \\
\text { from e. coli. }\end{array}$ & $296-329$ & $\begin{array}{l}\text { CVIKNSVIGDDCEISPY } \\
\text { TVVEDANLAAACTIGPF }\end{array}$ \\
\hline
\end{tabular}

